\title{
AVALANCHAS Y CORRIENTES DE BARRO EN CHILE
}

por Guenady Golubey

En las montañas, las avalanchas y las corrientes de barro figuran entre los fenómenos más destructivos. Demuelen construcciones, caminos $\mathrm{y}$, muchas veces, producen víctimas humanas. Las medidas de defensa en contra de estos fenómenos son, por lo general, costosas y no dan garantía de seguridad absoluta. Por ello es más razonable apreciar por anticipado el peligro que pueden representar para construcciones futuras. Cuando el peligro es evidente todo aconseja cambiar su ubicación o, en caso contrario, elaborar proyectos de defensa. Cuando la construcción ya existe en una zona de peligro conviene tomar medidas defensivas y preventivas. Estas resultan particularmente complejas cuando se desconoce el régimen de los fenómenos que inciden en estos procesos en una región geográfica determinada.

Este trabajo estudia las características generales de las avalanchas y las corrientes de barro en el territorio chileno. Si bien por el momento las regiones montañosas del país están casi deshabitadas, existen allí establecimientos mineros, caminos, ferrocarriles, plantas hidroeléctricas, centros de esqui y andinismo que están amenazados por ellas. A medida que la industria de Chile se desarrolle, la colonización de nuevos territorios de montaña es inevitable y con ello aumentará el peligro real de avalanchas y corrientes de barro.

A pesar de las víctimas y del daño que causan estos fenómenos, no existen estudios especiales al respecto. Los antecedentes que hemos recogido son muy escasos y se completan con observaciones personales hechas en todo el pais durante el año 1966. Lamentablemente no existen estaciones meteorológicas de alta montaña, ni observaciones sobre el espesor de la capa de nieve anual. Por ello el único método que permite describir el país desde el punto de vista que nos interesa es el análisis geográfico complementado con los datos que logramos recopilar. 
Como los factores que generan las avalanchas y corrientes de barro son distintos, la característica de los dos fenómenos se presentan por separado, aunque a veces la misma quebrada produce tanto avalanchas como corrientes de barro.

Antes de abordar directamente el tema quisiera agradecer sinceramente al entonces director del Instituto de Geografía de la Universidad de Chile Dr. Rómulo Santana Aguilar así como a todo el personal de dicho centro universitario. Igualmente deseo expresar mi reconocimiento al presidente del Comité de Seguridad en Montaña Sr. Eneas Valenzuela Pizarro y todas las personas que ayudaron al autor en su trabajo durante su permanecia en Chile.

\section{LAS AVALANCHAS}

Avalancha o rodado, es la masa de nieve que se desliza por la superficie inclinada de una pendiente de montaña. El volumen de la masa que se despeña puede alcanzar y aun superar un millón de metros cúbicos. Debido a la importancia de su masa y a la velocidad que adquieren las avalanchas poseen una enorme capacidad destructiva.

La avalancha surge cuando se rompe el equilibrio de la capa de nieve en una ladera. Su formación requiere entonces, como condiciones básicas, que la capa de nieve sea espesa y que la inclinación de la ladera sea considerable (pero no excesiva). La nieve se acumula generaImente en las formas cóncavas del relieve que vamos a denominar hoyas de acumulación de avalanchas. Los factores principales de la formación de avalanchas son de dos tipos: los climáticos, que condicionan el desarrollo de la capa de nieve; y los geomorfológicos, que determinan su acumulación y movimiento.

A veces también la vegetación tiene importancia esencial.

Atendiendo el complejo de factores físico-geográficos, que determinan el régimen de avalanchas, la Cordillera andina de Chile puede ser dividida en cuatro dominios: A) Sector de clima tropical desértico-montañoso, de relieve mediano o débilmente desmembrado (1) $\left(17^{\circ}-27^{\circ}\right.$ lat. S.) ; B) Sector de clima mediterráneo con un relieve fuertemente desmembrado $\left(27^{\circ}-36^{\circ}\right.$ lat. S); C) Sector de clima templado húmedo con relieve medianamente desmembrado $\left(36^{\circ}-41^{\circ}\right.$ lat. $\left.S\right)$; D) Sector de clima oceánico húmedo y fresco con relieve de mediano o fuerte desmembramiento $\left(41^{\circ}-56^{\circ}\right.$ lat. $\left.\mathrm{S}\right)$.

\section{A. El dOMinio de clima tropical desÉRtico-Montañoso de reliEve MEdiano O DÉBILMENTE DESMEMBRADO $\left(17^{\circ}-27^{\circ}\right.$ LAT. S)}

Abarca casi toda la región geográfica del Norte Grande. Allí las precipitaciones caen durante el verano en forma de lluvia aún en los lugares muy elevados. Las

(1) El grado del desmembramiento del relieve fue tomado por el autor con los siguientes limites: fuerte cuando los valles tienen profundidades superiores a $1.000 \mathrm{~m}$; mediano, entre 500 y $1.000 \mathrm{~m}$; débil, cuando las profunđidades son inferiores a $500 \mathrm{~m}$. 
nevadas de inviernos son raras y de débil intensidad. La fuerte radiación solar y la sequedad del aire producen una rápida ablación de la nieve. Desde el punto de vista climático las condiciones de formación de avalanchas son extremadamente desfavorables.

La región se caracteriza por tener formas de relieve suaves. Sin embargo, los volcanes que presentan laderas escarpadas con alturas superiores a $5.000 \mathrm{~m}$. pueden mantener capas de nieve de temporada. Son al parecer los únicos lugares que presentan peligro de avalanchas en la región. Pero ellas deben ser raras y de escaso volumen. Carecemos totalmente de datos al respecto.

En general pensamos que las montaffas del Norte Grande no son peligrosas en lo que a avalanchas se refiere.

\section{B. EL DOMINIO DEL CLIMA MEDITERRANEO CON RELIEVE FUERTEMENTE DESMEMRRADO $\left(27^{\circ} 36^{\circ}\right.$ LAT. S)}

Abarca las regiones geográficas del Norte Chico y Chile Central. Como veremos más adelante, presenta condiciones naturales extraordinariamente favorables para la formación de avalanchas. En esas altas montañas hay territorios ya colonizados por el hombre, el que entra inevitablemente en lucha con los rodados de nieve. Casi todos los casos de catástrofes de avalanchas conocidas en Chile han sucedido en esta región. Su descripción requiere entonces la mayor atención.

\section{a) Factores climáticos en la formación de avalanchas.}

Desgraciadamente, el conocimiento de las condiciones climáticas de la alta montaña de Chile, incluso de su parte central, son muy precarios. Para caracterizar el territorio que se describe, utilizamos los datos de la estación meteorológica de El Teniente (Sewell) que pertenece a la Braden Copper Company. El Teniente está situado en la parte sur de la región y, naturalmente, no puede ser representativa para todo el sector que nos ocupa.

\section{Las precipitaciones.}

Sewell, a $2.134 \mathrm{~m}$. de altura $\left(36^{\circ} 06^{\prime}\right.$ lat. $\mathrm{S} .70^{\circ} 22^{\prime}$ long. W. recibe en el perfodo de mayo a diciembre el $92 \%$ de las precipitaciones anuales. De ellas, el $65 \%$ se concentra entre los meses de junio y septiembre. Sobre los $2.500-9.000 \mathrm{~m}$. todas las precipitaciones del año caen en forma de nieve (Lliboutry 1952). Bajo dicha altura, las precipitaciones pueden ser de importancia como ocurrió durante el temporal del 9-16 de agosto de 1965, que comprometió la mayor parte del pafs. En esa ocasión llovió en Sewell cuatro días consecutivos con montos diarios de 35,8 a $48,8 \mathrm{~mm}$. Tales lluvias pueden producir avalanchas mojadas aun en pleno invierno, como efectivamente ocurrió. 


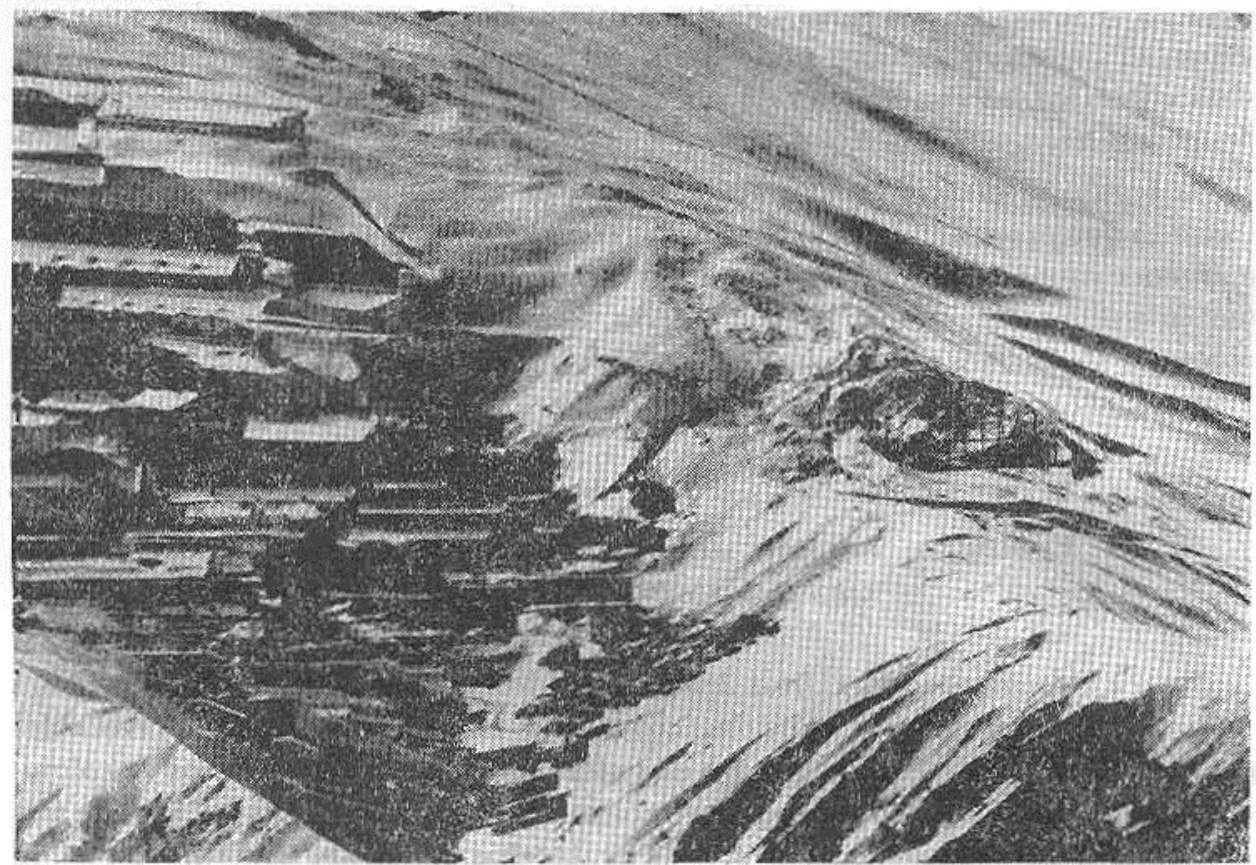

Fig. 1. El Teniente. Agosto 1955.

Clisé Braden Copper.

En este sector las nevadas no son frecuentes, ni tienen larga duración. Están separadas por períodos bastantes prolongados de buen tiempo con sol. En Sewell, entre junio y agosto se registran en promedio 8 días de nevadas por mes contra 10 dias claros con nubosidad inferior a $2 / 10$.

A la misma altura el monto de precipitaciones anuales aumenta hacia el sur. Lo mismo pasa con el período de peligro de avalanchas. En la hoya del Aconcagua (33 lat. Sur) a $2.200 \mathrm{~m}$. de altura caen $450 \mathrm{~mm}$. entre junio y septiembre (L. Lliboutry 1956) y en Sewell ( $34^{\circ}$ lat. Sur) a $2.134 \mathrm{~m}$. caen, en el mismo período, $649 \mathrm{~mm}$. Nuestras observaciones en el terreno y desde el avión confirman estos antecedentes. (Fig. 1).

Las nevadas no son de larga duración ni frecuentes pero son, en cambio, intensas de acuerdo a los datos de L. Lliboutry para Portillo (hoya de Aconcagua, $2.700 \mathrm{~m}$. de altura) .

\begin{tabular}{cccc}
\hline $\begin{array}{c}\text { Fecha de la } \\
\text { nevazon }\end{array}$ & $\begin{array}{c}\text { Duración } \\
\text { horas }\end{array}$ & $\begin{array}{c}\text { Precipitaciones } \\
m m .\end{array}$ & $\begin{array}{c}\text { Intensidad promedia } \\
\text { mm. hora }\end{array}$ \\
\hline 23 a 26 del v-1958 & 72 & 236 & 3,3 \\
25 a 26 del v-1964 & 22 & 136 & 6,2 \\
\hline
\end{tabular}


Dicho autor estima la intensidad promedio de nevazones en Portillo en $\mathbf{2 , 3}$ $\mathrm{mm} /$ hora.

En Sewell el 12 de agosto de 1965 durante tres horas la intensidad de nevazón fue de 3,5 mm/hora. En la misma localidad para un perfodo de observaciones de 30 años (1916-45) las cantidades máximas absolutas de precipitaciones diarias fueron las siguientes:

\begin{tabular}{lrrrrr}
\hline & Junio & Julio & Agosto Septiembre Octubre \\
\hline Precipitaciones, mm. & 137,0 & 1858,7 & $\mathrm{I} 27,0$ & 148,0 & 127,0 \\
Intensidad promedio, mm/hora & 5,7 & 6,6 & 5,3 & 6,0 & 6,3 \\
\hline
\end{tabular}

Basándonos en la suma mensual promedio de precipitaciones y en la cantidad de días cuya intensidad es superior a $0,1 \mathrm{~mm} /$ día podemos calcular el promedio de precipitaciones diarias en Sewell.

\begin{tabular}{|c|c|c|c|c|c|}
\hline \multirow{2}{*}{ Precipitaciones, mm } & \multirow{2}{*}{ Junio } & \multirow{2}{*}{$\begin{array}{l}\text { Julio } \\
250,1\end{array}$} & \multicolumn{3}{|c|}{ Agosto Septiembre Octubre } \\
\hline & & & 198,2 & 162,2 & 88.7 \\
\hline \multicolumn{6}{|l|}{ Dias con precipitaciones superiores } \\
\hline a $0,1 \mathrm{~mm} / \mathrm{día}$ & 7,7 & 10,4 & 8,5 & 8,4 & 5,8 \\
\hline Promedio de precipitaciones diarias, $\mathrm{mm}$ & 25 & 24 & 23 & 19 & 15 \\
\hline
\end{tabular}

Si consideramos también, los dias con intensidad muy baja, podemos concluir que el promedio diario de precipitaciones que forman las avalanchas son muy significativas porque las precipitaciones invernales tienen alta intensidad horaria y diaria, lo que favorece enormente la formación de avalanchas.

Por desgracia, casi no disponemos de datos sobre la capa de nieve. Las altas temperaturas del aire, la escasa humedad y la fuerte insolación en esta región hace presumir que una considerable porción de la nieve depositada se evapora o se derrite. Esto hace imposible calcular la profundidad de la nieve en base a los datos de precipitaciones mensuales. Además, las nevadas se acompañan generalmente por fuertes vientos que crean enormes irregularidades en la distribución de la capa de nieve. No obstante, podemos hacer cálculos aproximados y de simple referencia para algunas nevazones considerando las siguientes condiciones: la densidad de la nieve recién depositada es de $0,1 \mathrm{gr} / \mathrm{cm}^{3}$, ésta no se trasladada por el viento, no hay ablación. En esas condiciones Portillo haủn recibido entre el 23 y 26 de mayo de $1953,236 \mathrm{~cm}$. de nieve fresca y $136 \mathrm{~cm}$. entre el 25 y el 26 de mayo de 1954. 
En Sewell antes de la nevazón del 9 de agosto de 1965 habia solamente $18 \mathrm{~cm}$. de nieve y el 15 de agosto, cuando se produjeron fuertes avalanchas, la profundidad de la capa de nieve era ya de $188 \mathrm{~cm}$. Solo el día 12 de agosto se depositaron $62 \mathrm{~cm}$. Si suponemos, con referencia a observaciones hechas en otras partes, que las ventiscas pueden concentrar en las hoyas de acumulación de avalanchas espesores de nieve cinco veces superiores a los que se registran en una plaza horizontal, es posible suponer que en ciertas hoyas la profundidad excede a $5 \mathrm{~m}$.

\section{Las temperaturas.}

A primera vista las temperaturas invernales del aire en la región estudiada parecen ser paradojalmente altas. En Sewell el promedio diario, y aun el promedio de las mínimas están sobre cero en todos los meses invernales, hecho que parece no concordar con la existencia de una capa de nieve constante. Los datos promedios de la temperatura del aire en Sewell para el periodo de 1916-45 son las siguientes:

\begin{tabular}{|c|c|c|c|c|c|c|}
\hline & Mayo & Junio & Julio & Agosto & Septbr. & $O_{c t b r}$ \\
\hline $\begin{array}{l}\text { Temperatura promedio mensual } \\
\text { del aire. } \\
\begin{array}{ll}\text { máxima } \\
\text { mínima }\end{array}\end{array}$ & $\begin{array}{r}7,5 \\
12,4 \\
3,8\end{array}$ & $\begin{array}{l}4,1 \\
8,6 \\
0,4\end{array}$ & $\begin{array}{l}4,3 \\
9,0 \\
0,5\end{array}$ & $\begin{array}{l}4,3 \\
9,4 \\
0,4\end{array}$ & $\begin{array}{r}6,2 \\
11,5 \\
1,8\end{array}$ & $\begin{array}{r}8,6 \\
14,1 \\
4,0\end{array}$ \\
\hline $\begin{array}{l}\text { Cantidad de dias con temperatu- } \\
\text { ras bajo cero }\end{array}$ & 6,0 & 14,3 & ]4,I & 14,3 & 10,7 & 5,4 \\
\hline
\end{tabular}

La temperatura mínima absoluta fue de $12,5^{\circ} \mathrm{C}$.

Temperaturas del aire tan altas en combinación con la capa de nieve bastante profunda y constante nos llevan a importantes conclusiones.

En el balance de masa de la capa de nieve predomina el monto de entradas (precipitaciones sólidas) en comparación con el monto de gastos (ablación). Hay que añadir que quizás la temperatura del aire no sea el mejor índice de balance calórico de la capa de nieve (sobre este tema volveremos más adelante).

Los gradientes térmicos en la capa de nieve son pequeños y ella se desarrolla empaquetándose. En este caso no tiene lugar la recristalización que produce la formación de las capas friables, por las cuales caen las avalanchas, hecho muy típico para muchas regiones del mundo. Esta recristalización puede ocurrir solamente en las partes más altas de la cordillera caracterizadas por fríos intensos.

\section{La humedad del aire.}

En Sewell la humedad relativa promedia establecida en un periodo de 30 años, a las 19 horas, fue la siguiente: 


\begin{tabular}{ccccccc}
\hline & Mayo & Junio & Julio & Agosto & Septiembre Octubre \\
\hline$\%$ & 55 & 63 & 60 & 61 & 50 & 49 \\
\hline
\end{tabular}

Lamentablemente, no disponemos de antecedentes sobre los promedios de humedad absoluta, datos que tienen más importancia que los de la humedad relativa. La humedad absoluta determina el proceso predominante: evaporación desde la superficie de la nieve o condensación en ella. Con la temperatura del aire a $0^{\circ}$, la humedad absoluta máxima es igual a 6,11 milibares. Si la temperatura de la superficie de la capa de nieve es cero grado y la humedad absoluta del aire es inferior a $6,11 \mathrm{mb}$., la nieve se evapora. Si la humedad es superior a $6,11 \mathrm{mb}$. tiene lugar la condensación del agua del aire en la nieve. El efecto de estos procesos, tomándolos en las medidas de la masa, podría ser pequeño, pero, si lo referimos a las medidas del balance de calor, puede ser considerable. El calor latente de Ia fusión del hielo es $80 \mathrm{cal} / \mathrm{gr}$., el de la evaporación del agua de $0^{\circ}$ es $597 \mathrm{cal} / \mathrm{gr}$., el de la sublimación del hielo de $0^{\circ}$ es $677 \mathrm{cal} / \mathrm{gx}$. Cuando la temperatura de la superficie de la capa de nieve sea $0^{\circ}$, se puede decir que una parte de la nieve se sublima desde la superficie y la otra se evapora desde el agua que se ha producido debido al derretimiento. Entonces podemos considerar que el calor latente del proceso mixto sublimación-evaporación es igual a $640 \mathrm{cal} / \mathrm{gr}$. aproximadamente. Vemos que este proceso gasta en calor ocho veces más que la fusión, de modo que la sublimación disminuye considerablemente la intensidad de ablación de la nieve. La condensación, al contrario, la aumenta.

Cuando el aire está seco y sus temperaturas son ligeramente superiores a $0^{\circ}$, ia fusión puede faltar por completo y debido a los grandes gastos de calor la sublimación no puede ser alta. P. Kuzmin (1961) establece que, cuando el balance de radiación solar sea igual a cero y la humedad relativa del aire igual a $50 \%$, la fusión empieza con la temperatura del aire a más de $3,3^{\circ} \mathrm{C}$. Si la temperatura y la humedad aumentan tendrán Iugar tanto la sublimación como la fusión, aunque la primera disminuya mucho la intensidad de la ablación. Por fin, cuando la humedad absoluta sea superior a $6,11 \mathrm{mb}$. y la temperatura se encuentra sobre cero grados tendrán lugar tanto la fusión como la condensación que aumentarán considerablemente la intensidad de la ablación.

Debido a la baja humedad relativa en Sewell (ver más arriba) podemos suponer que los efectos térmicos de sublimación en la conservación de la capa de nieve tienen una gran importancia.

Para evaluar la influencia compleja de temperatura y humedad del aire $\mathrm{V}$. Puzanov (1956) empleó el término de temperatura real equivalente:

$$
t r=t+\frac{0,623(e-6,11) L}{(p-e) C p+0,623 e C w}
$$


$t$ : es la temperatura del aire; $e$ : la humedad absoluta del aire en milibares; $L$ : el calor latente de vaporización; $p$ : la presión atmosférica; $C p$ : capacidad calorifica del aire seco con la presión constante; $C w$ : la capacidad calorifica del vapor de agua. El segundo sumando de la parte derecha de la fórmula nos expresa el efecto de la condensación-sublimación.

A base de esta ecuación V. Puzanov construyó un nomograma que permite calcular tanto la temperatura real equivalente como la proporción de la sublimación (o la condensación) y la fusión en el proceso de ablación. La influencia de la radiación solar no se toma en cuenta.

En el mes de agosto de 1965 la temperatura promedia en Sewell fue $4,6^{\circ}$, y la humedad absoluta promedia 4,90. Según el nomograma de Puzanov la temperatura real equivalente fue $2,4^{\circ}$. De la cantidad total de nieve que desaparecio, $9 \%$ se sublimó y $91 \%$ se derritió. No es difícil calcular que la sublimación gastó $44 \%$ del calor que recibió la nieve debido a la influencia compleja de la temperatura y humedad del aire. Sin embargo, hay que añadir que la radiación solar aumenta solamente la fusión. Así, el papel de sublimación en el balance de calor total de la ablación fue menor a $44 \%$.

Para la ilustración del efecto térmico de sublimación damos a continuación los datos de las horas precisas, en que la humedad fue reducida. (Fig. 2) .

EL EFEGTO TERMICO DE IA SUBLMMACION DE LA CAPA DE NIEVE EN SEWELL, AÑo 1965

\begin{tabular}{|c|c|c|c|c|c|c|}
\hline \multirow[t]{2}{*}{ Fecha } & \multirow[t]{2}{*}{ Hora } & \multirow[t]{2}{*}{$\begin{array}{l}\text { Temperatura } \\
\text { del aire }\end{array}$} & \multirow{2}{*}{$\begin{array}{c}\text { Humedad } \\
\text { absoluta } \\
m b .\end{array}$} & \multirow{2}{*}{$\begin{array}{c}\text { Temperatura } \\
\text { real } \\
\text { equivalente }\end{array}$} & \multicolumn{2}{|c|}{$\begin{array}{l}\text { Papel de sublimacion } \\
\quad \text { en el balance de: }\end{array}$} \\
\hline & & & & & $\operatorname{mas} a \%$ & calor $\%$ \\
\hline $6 \mathrm{vIII}$ & 14 & 15,2 & 3,2 & 10,4 & 6 & 34 \\
\hline $18 \mathrm{vIII}$ & I4 & 5,2 & 3,7 & 1,2 & 30 & 77 \\
\hline 25 vIII & 14 & 10,0 & $\mathbf{2 , 6}$ & 4,0 & 18 & 63 \\
\hline
\end{tabular}

Del análisis de estos momentos seleccionados resultà también evidente la influencia de la sublimación que juega el papel de "desfalcadora" de calor.

Nos queda aún por averiguar la frecuencia en que se produce la sublimación o la condensación. Para estos cálculos hemos utilizado los datos de Sewell del mes de agosto de 1965.

LA CANTIDAD DE DIAS CON SUBLIMACION O CONDENSACION DURANTE LA ABLACION DE I,A CAPA DE NIEVE. SEWELL, AGOSTO DE 1965

\begin{tabular}{cccc}
\hline Hora & $\begin{array}{c}\text { Sublimación } \\
\text { sin fusion }\end{array}$ & $\begin{array}{c}\text { Sublimación } \\
\text { y fusión }\end{array}$ & $\begin{array}{c}\text { Condensación } \\
\text { y fusión }\end{array}$ \\
\hline 8 & 22 & 8 & 1 \\
14 & 3 & 21 & 7 \\
\hline
\end{tabular}



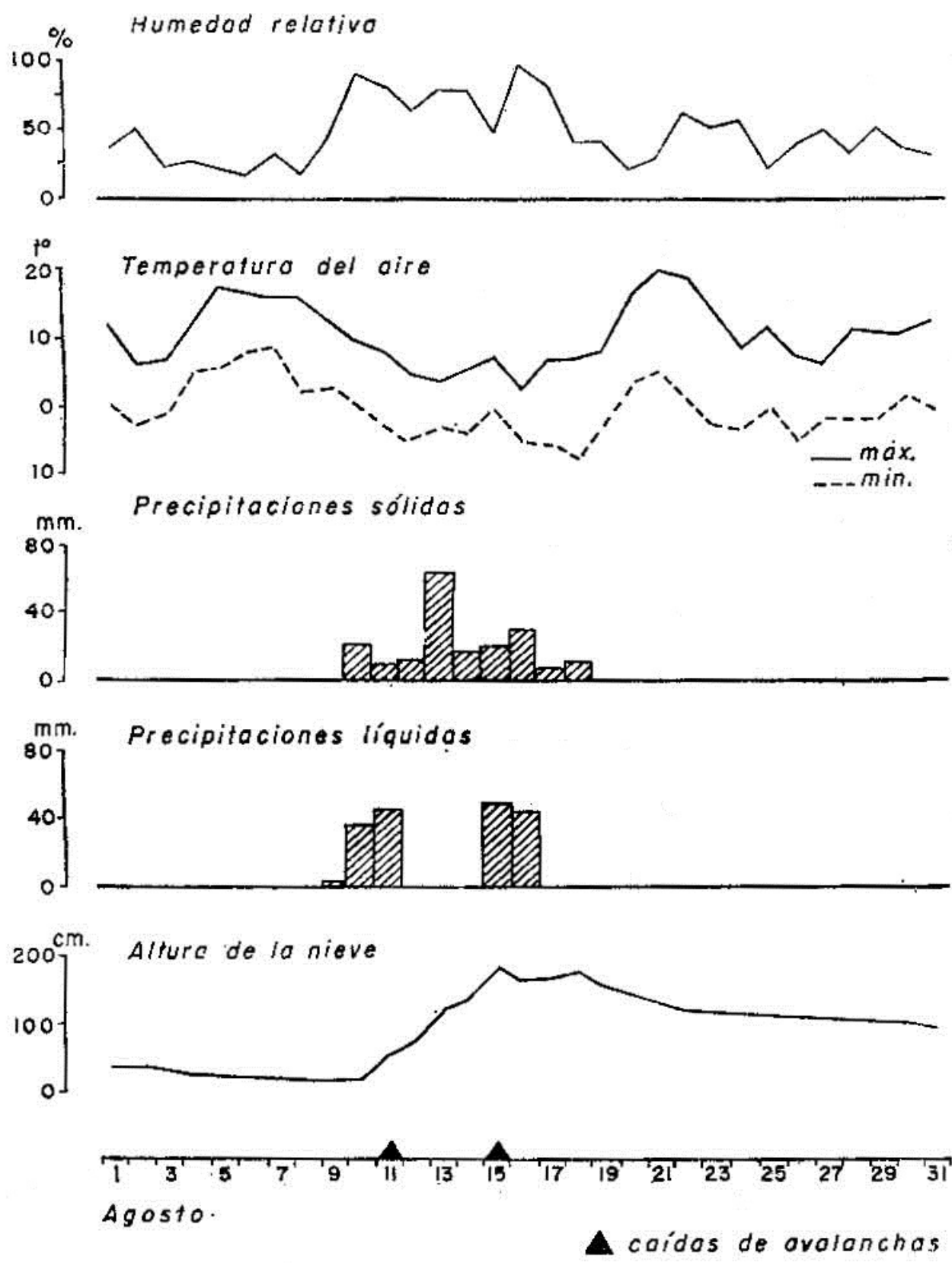

Dibujo A.Ironzo

Fig. 2. Sewel. 1965. 
Vemos que solamente en $15 \%$ de los casos la fusión se acompañaba de condensación con separación complementaria del calor.

El hecho de analizar los datos de la humedad del aire y su comparación con regiones más húmedas nos permite llegar a las siguientes conclusiones:

-Con la temperatura del aire bajo ceno la sequedad del aire favorece una elevada ablación de la capa de nieve debido a la sublimación

- Con la temperatura del aire sobre cero la sequedad del aire conduce también la sublimación de la nieve, pero este hecho, al contrario, favorece la menor ablación de la nieve depositada.

\section{El papel del viento.}

En la formación de la capa de nieve y las avalanchas el viento se manifiesta en:

-el transporte de la nieve desde las formas de relieve convexas a las cóncavas, donde se acumula gran espesor de la nieve, que pueden formar después las avalanchas;

-la sublimación excesiva de nieve durante las ventiscas;

-la formación de las cornisas de nieve, que se producen al derrumbarse las avalanchas.

En base a nuestras observaciones podemos concluir que el papel del viento en estos aspectos es de verdadera importancia. Su acción se traduce en la formación de potentes cornisas en las laderas de sotavento, en la desigual distribución de la nieve en el territorio y en la notable disminución de la nieve durante los períodos sin precipitaciones. Además los vientos fuertes causan frecuentemente la formación de tablones de nieve. No conocemos casos de avalanchas tipo tablón de nieve en Chile. Lliboutry (1956) tampoco los menciona. Al parecer las temperaturas del aire en Chile no son suficientemente bajas para la formación de estos fenómenos.

\section{La nubosidad.}

En promedio la atmósfera de invierno en las montañas de la región estudiada se observa despejada. En Sewell, la nubosidad promedia mensual a las 13 hrs. es la siguiente (en décimas) :

\begin{tabular}{cccccc}
\hline Mayo & Junio & Julio & Agosto & Septiembre & Octubre \\
\hline 6,0 & 6,3 & 5,4 & 5,8 & 5,0 & 5,3 \\
\hline
\end{tabular}


Cada mes de la parte invernal del año tiene un promedio de 10 dfas claros y otros 10 con nubosidad variable de 2 a 8 décimas. La gran cantidad de días claros y la alta posición del sol ejercen considerable influencia en el régimen de avalanchas:

-los cálculos aproximados muestran que el balance de radiación solar es positivo casi cada día, hecho que produce la ablación de la nieve durante todo el invierno;

- la distribución de las temperaturas dentro de la capa de nieve debe ser homogénea. Gracias a esto se forman avalanchas de recristalización (lo mismo hemos dicho antes por otra razón) ;

- hay grandes diferencias del régimen de nieve y avalanchas entre las laderas de exposición sur y norte. El 15 de julio de 1966 durante un vuelo realizado sobre la cuenca del río Maipo pudimos observar que en las laderas de exposición norte habian caído muchas avalanchas mojadas mientras que en las laderas opuestas habian caído especialmente avalanchas secas o húmedas.

El cálculo aproximado del balance de calor de la capa de nieve en Sewell que hemos hecho para el período comprendido entre el 20 de agosto de 1965 (1) que el balance de calor fue positivo para 16 de los 20 dias considerados. En estas condiciones la ablación era casi permanente, y el factor principal de la existencia de la capa de nieve estable residia sólo en la intensidad de las nevadas (esto confirma lo que se ha dicho anteriormente). Además, los cálculos mostraron que el balance de radiación solar y el intercambio término turbulento entre la superficie de la nieve y el aire son más o menos iguales. En estas circunstancias la sublimación gasta cerca de $20 \%$ de todo el calor recibido, antecedente que precisa los datos que ya hemos dado.

El análisis de las condiciones meteorológicas precedentes nos permite deducir los principales tipos de tiempo que determina el régimen de nieve y avalanchas para la alta montaña de Chile Central:

- la acumulación de la nieve se produce durante las nevadas intensas. Durante la nevazón se generan numerosos rodados de nieve fresca húmeda;

-los periodos de acumulación nival están separados por otros de ablación más prolongada. Durante ellos, a causa de las altas temperaturas del aire y la influencia de una fuerte insolación, se pueden producir avalanchas mojadas.

Otros tipos de avalanchas (de tablón, pulvurulenta, de recristalización, etc.), no son características para Ia región debido a las condiciones climáticas ya examinadas.

(l) Los cálculos se han hecho en base de los datos meteorológicos según el método elaborado por P. Kuzmin (1961). No damos aquí la descripción del método mismo, puesto que no tiene la conexión directa con el tema del trabajo actual. 
b) Factores geomorfológicos de la formación de avalanchas.

La región estudiada se distingue por la importancia de sus alturas absolutas y relativas con referencias a Chile y toda América. La orogénesis andina trajo como consecuencia una vigorosa acción de la erosión fluvial y glacial. Pero a pesar de su altura, el desmembramiento en la Cordillera no es tan considerable como en los Alpes o en el Cáucaso.

\section{Los rasgos del relieve.}

Cuando se observa la cordillera desde el aire llama la atención ver líneas de crestas muy uniformes en su altura, los cerros que sobresalen del conjunto son más bien la excepción. La misma regularidad se constata en las superficies altas, poco inclinadas y de tamaño considerable, cuyos bordes están cortados por cañones profundos de laderas escarpadas. Muchas de estas superficies son mesetas de origen volcánico, que se formaron debido a efusiones de lava relativamente re. cientes y a la acumulación de cenizas volcánicas.

Las formas cóncavas del relieve se formaron parcialmente por la acción erosiva de los glaciares y las aguas corrientes. Son Ios circos y los embudos torrenciales. Ellas se comportan como zonas de acumulación de avalanchas. Nuestras observaciones nos hacen creer que la mayor cantidad de aludes se generan en formas relacionadas con la erosión aluvial y con los derrumbes. Tales avalanchas son más frecuentes, pero de menor dimensión que los que se originan en los circos glaciales. Los grandes aludes se forman, en este último caso, por Ia suma sincrónica de rodados de varios embudos vecinos.

Los valles de los rios son, por lo general, estrechos, profundos y de laderas escarpadas. Desniveles de $1-2 \mathrm{Km}$. y más son frecuentes. Dicha profundidad y la importancia de las escarpas determinan la gran energfa de las avalanchas.

La disposición monoclinal de los estratos condiciona perfiles de ladera sin accidentes. Su incidencia en las avalanchas depende de la inclinación de la ladera. El otro borde clel valle, que recorta los afloramientos, tiene por lo general un perfil escalonado. El peligro de avalanchas es mayor en el primer caso que en el segundo.

Debido a la actividad de glaciares cuaternarios muchos valles tiene el perfil en forma de "U", morfología que ofrece condiciones para las llamadas avalanchas de salto.

Esta breve descripción de los rasgos del relieve que influyen a la formación de avalanchas atañe sólo a la parte central más alta de la región (hoyas de los ríos Aconcagua, Maipo y Cachapol-Tinguiririca). Hacia el norte y hacia el sur de este sector las alturas son menores. Con ello disminuye en algo el peligro de avalanchas, pero los rasgos típicos de relieve, que influyen en la actividad de los aludes, son semejantes a los de la parte central. 
2. La influencia de la alturay disposición del relieve.

Además de la influencia directa, el relieve actúa en el régimen de avalanchas indirectamente por medio de modificación de las condiciones meteorológicas. En los relieves de mediana altura esto se manifiesta en el menor espesor de la capa de nieve en las laderas de exposición norte y, también, en la mayor frecuencia de avalanchas mojadas. En los relieves de mayor altura, la influencia se expresa en la correlación entre la cantidad de la nieve calda y la situación de las sierras circundantes. Así, por ejemplo, durante reconocimientos aéreos hechos el 24 de agosto y el 30 de septiembre de 1966, pudimos observar, que en la hoya del rio Huasco las sierras occidentales de la Cordillera de los Andes tenían más nieve que la línea divisoria principal de aguas. Un hecho semejante anotamos el 15 de julio de 1966 durante otro vuelo de observación en la región de Santiago. Es evidente, en estos casos, que las sierras avanzadas interceptan una porción importante del agua que aportan las masas de aire que vienen desde el Paclfico. La Cordillera de la Costa ejerce también notable influencia sobre la distribución de precipitaciones. La comparación de las hoyas del Mapocho y del Maipo en la región de Santiago, permite ilustrar esta influencia. La Cordillera de la Costa se interpone con mayor eficacia entre el Pacífico y la cuenca del Mapocho, que entre el Pacífico y la cuenca del Maipo. Como resultado de esto la segunda tiene anualmente mucho más nieve que la primera. Este hecho fue anotado por L. Lliboutry y se confirma con nuestras observaciones durante el vuelo del 15 de julio de 1966. La línea de nieve en la hoya del Maipo está situada $400 \mathrm{~m}$. más abajo, que en la del Mapocho, y la cantidad de avalanchas en la primera es mayor.

Si estos hechos son la manifestación de una ley general podemos suponer que la zona de mayor acumulación nival está desplazada al $W$. de la línea divisoria principal de aguas de la Cordillera de los $\Lambda$ ndes y que, por lo tanto este desplazamiento es también característico en cuanto a la zona de peligro de avalanchas.

Ast, la influencia del relieve en la actividad de los aludes en la región estudiada puede caracterizarse por los rasgos siguientes:

- El fuerte desmembramiento del relieve asegura un alto grado de peligro de avalanchas en los valles fluviales.

- Aun en la parte más alta de la región existen mesetas, de superficie considerable, que no representan peligro. (Fig. 3) .

- El máximo de actividad de los aludes se encuentra en la parte central y más alta de la región (cuencas de los ríos Aconcagua, Maipo, CachapoalTinguiririca) . (Fig. 4).

- Es probable que la zona de máximo peligro de avalanchas esté desplazada hacia el oeste de la línea divisoria principal de aguas en la Cordillera de los Andes. 


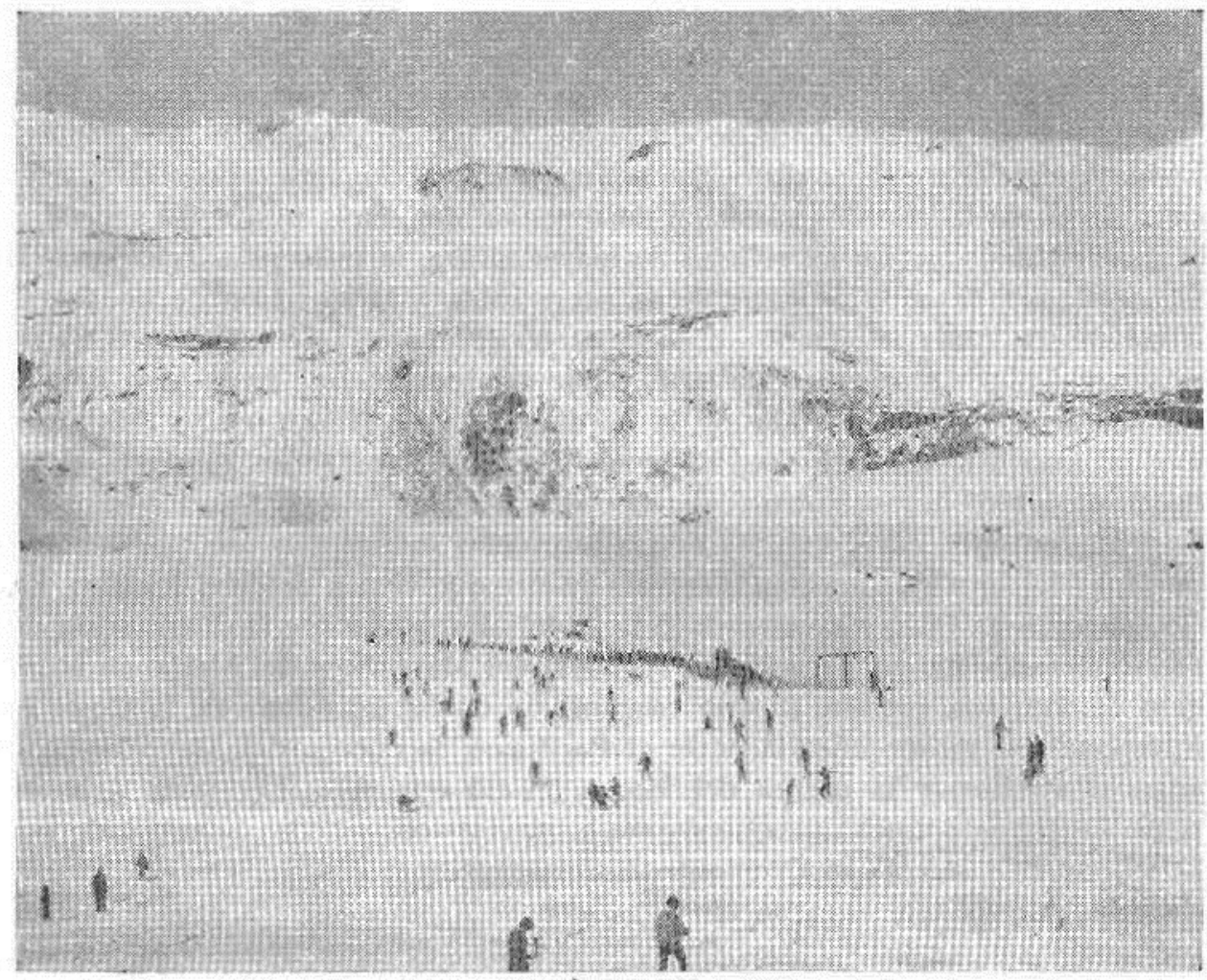

Fig. 3. Farellones. Valle del río Mapocho.

\section{El rol de la vegetación.}

El bosque sirve como defensa natural contra las avalanchas. En la región estudiada los bosques ocupan solamente la parte austral de la región, lo que también favorece mucho la actividad de los aludes en todo el sector septentrional. Las condiciones naturales restantes de la región estudiada favorecen ampliamente la actividad de las avalanchas.

C. Antecedentes históricos de algunas avalanchas y limites de la zona de aludes.

Se conocen muy pocos casos de caída de aludes en la región estudiada, aunque ellos ocurren frecuentemente cada invierno. Esto se explica por la falta de información de tales casos y por la ausencia de población en la alta montaña de Chile.

- Lo Valdes, valle del Maipo. EI 7 de julio de 1953 una avalancha mató a 23 escolares. Antes del rodado nevó mucho con tiempo nuboso y temperatura 




Fig. 4. Portillo, Valle del rio Aconcagua. 
relativamente alta. La zona de formación de la avalancha estaba constituida por pizarra meteorizada en menudas esquirlas que disminulan la fricción. En la parte inferior de la ladera el coeficiente de fricción era menor aún puesto que el rodado pasó por la superficie de deslizamiento del alud anterior. Además, el perfil convexo de la ladera favoreció también el rodado (Lliboutry, 1956).

- Portillo, valle del Aconcagua, Il de agosto de 1965. Esos dias las nevadas y y lluvias fuertes abarcaban la mayor parte del país. Según el diario "El Mercurio" del 12 de agosto de 1965, durante el periodo comprendido entre el 8 y el 11 de agosto cayeron en Santiago $89,8 \mathrm{~mm}$. de precipitaciones. Esto significa que en la montaña dicha cantidad puede aumentarse sin exageración a $200 \mathrm{~mm}$. En cuatro dias de temporal perecieron en Chile 35 hombres y 15 mil personas sufrieron daños. El estrago del temporal fue mayor que los efectos del fuerte terremoto del 28 de marzo de 1965. El 11 de agosto a las 5 de la mañana, en Portillo, una avalancha destruyó un edificio construido en 1922. Murieron 5 esquiadores de diferentes países. A menos de un año del Campeonato Mundial de Esqui, en un mismo dfa fueron destruidos cinco andariveles, es decir, todos los que existían en aquella región.

Otras avalanchas destruyeron $o$ aplastaron tramos del ferrocarril trasandino y del camino.

En el curso superior del río Mapocho, a pesar de las construcciones de defensa, fueron destruidos 8 apoyos del andarivel de carga de la mina "Disputada de Las Condes" y en la zona de la mina hubo 6 muertos y 3 heridos.

Las mayores avalanchas de agosto del 65 cayeron en la zona de la mina "El Teniente"; valle del Cachapoal. El gráfico de los elementos meteorológicos en Sewel (Fig. 5) muestra, que los aludes cayeron el 2 y el 15 de agosto a consecuencia de la enorme acumulación de nieve y la caida de lluvias. Gracias a las medidas tomadas por el Servicio de Seguridad de Avalanchas de la Braden Copper Company, no hubo víctimas.

El temporal con nevadas en la Cordillera y, por lo tanto con avalanchas, abarcó en el período del 8 al 16 de agosto de 1965 toda la parte central del país. Este fenómeno, con menor o mayor intensidad, se repite cada invierno, hecho que justifica nuestra intención de hacer un pronóstico territorial general del peligro de avalanchas a base del análisis sinóptico.

Según los datos de que disponemos, en el año 1966 murieron en Chile por efecto de Ias avalanchas 11 personas, de las cuales siete perecieron en la región estudiada. El 17 de abril hubo 4 personas muertas y 2 gravemente heridas en la zona de la mina "El Rosario", al sur de la región. El 12 de julio murieron 3 obreros en la zona de El Teniente. En los mismos dias fue interrumpido el tránsito del ferrocarril transandino debido a las acumulaciones de nieve.

No disponemos de datos de caldas de avalanchas en la parte septentrional de la región estudiada, en el territorio del Norte Chico. Nuestras observaciones de terreno en las cuencas de los ríos Limarl y Elqui permiten constatar que el 
peligro de avalanchas empiezan a $2.500 \mathrm{~m}$. de altura. Este limite baja en la hoya del Aconcagua a 1.700-1.500 m., aproximadamente. Las observaciones hechas desde el avión nos permiten decir que aunque la nieve en la cordillera aparece desde $\operatorname{los} 27^{\circ}$ de latitud $\mathrm{S}$. el peligro de aludes entre dicho paralelo y los $29^{\circ}$ parece ser esporádico. Huellas indudables de la actividad de avalanchas aparecen sólo al $\mathrm{S}$. de la hoya de Copiapó. Asi, la parte más septentrional de la región prácticamente no tiene peligro de aludes, pero a partir de la hoya de Huasco hacia el sur éste aumenta bruscamente.

\section{d) Los servicios de seguridad de avalanchas.}

Cualquiera empresa situada en una zona con scrio peligro de avalanchas, no puede prescindir del servicio de seguridad de aludes. No obstante, en Chile hay sólo dos servicios que funcionan en las minas de cobre en la región montañosa. Gracias al permiso de la administración de las compañías nos fue posible conocer la acción de estos servicios.

Uno de ellos es el que corresponde a la mina El Teniente. La población de Sewell, la mina y la planta de concentración del mineral se sitúan en zonas seguras, pero la saturación del reducido espacio en la montaña obligó a la ocupación de sectores que representan zonas de peligro. Además, las vías de comunicación se encuentran también sometidas, en algunos tramos, a la acción de aludes. Esto impulsó a la construcción de defensas y a la creación del Servicio de Seguridad de Avalanchas. Los deberes del Servicio son: observar el tiempo y la nieve, estimar diariamente el peligro de avalanchas, evacuar personas y vehículos de los lugares amenazados y programar las obras de defensa. Entre los materiales del servicio los más valiosos son los datos de las observaciones meteorológicas que se hacen permanentemente desde el año 1916. Las fotos que la compañía nos comunicó amablemente ilustran la acción de avalanchas y funcionamiento de las construcciones de defensa (Fig. 6). Entre ellas predominan las galerias sobre el ferrocarril, las redes de cable grueso para detener la nieve en la ladera y los diques.

Otro Servicio de Seguridad de Avalanchas existe en el yacimiento de cobre del Río Blanco (cuenca del río Aconcagua). Esta zona es muy peligrosa. El camino a lo largo del río cruza en un tramo de $28 \mathrm{Km}$. por 40 lugares de aludes. Durante el temporal de agosto de 1965 la población principal fue destruida parcialmente. El Servicio de Seguridad observa el tiempo y la nieve, previene los períodos de peligro, asegura el tránsito por el camino y hace los bombardeos profilácticos de las zonas de acumulación de nieve. A medida de que se acerca el peligro de avalanchas se dan sucesivamente tres alarmas. La primera, según el pronústico del tiempo con anticipación de 24 horas. Después de esta alarma se toman las medidas preparatorias para Ia evacuación de personas y vehículos de los lugares amenazados. La segunda alarma se da al comienzo de la nevazón. Todos los vehículos se colocan en refugios. La tercera coincide con el principio 


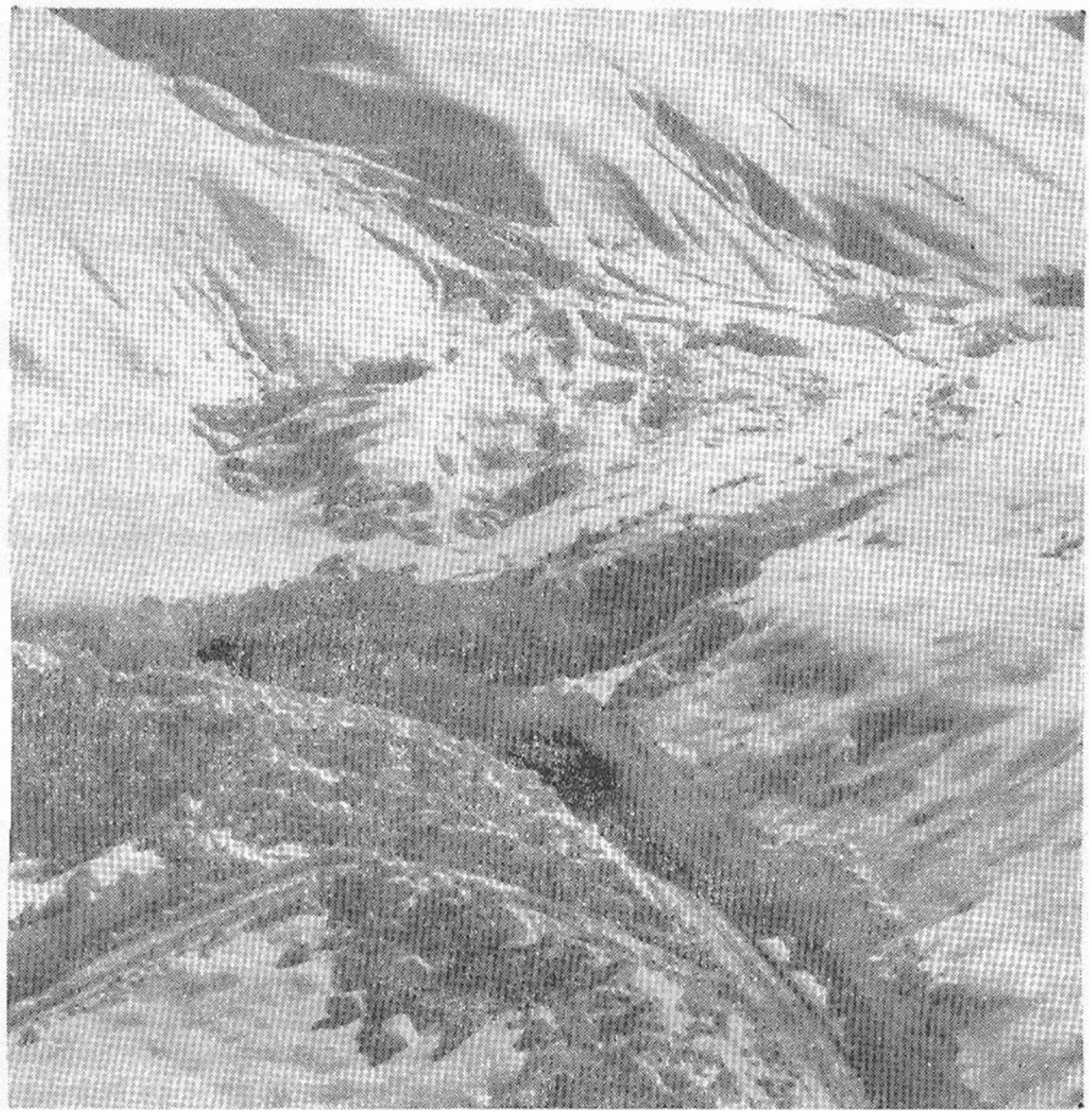

Fig. 5. EI Teniente. Avalanchas de agosto 1965.

Clisé Braden Copper.

del período de mayor peligro y se suspende completamente el tránsito por el camino.

El ferrocarril y el camino transandinos, que pasan a lo largo del río Aconcagua, también están amenazados por aludes. En el ferrocarril, el peligro es menor gracias a los túneles y galerías en los lugares de intersección del ferrocarril con las vías de aludes. El camino, en cambio, no tiene ninguna construcción de defensa, aunque se proyecta abrirlo para el tránsito en el invierno del año 1970. Sin la creación de un servicio de seguridad de avalanchas bien equipado, esta tarea nos parece irrealizable. (Fig. 7) .

Durante el Campeonato Mundial de Esquí de agosto de 1966 en Portillo, fue organizado un servicio especial para controlar avalanchas. A la cabeza de este 


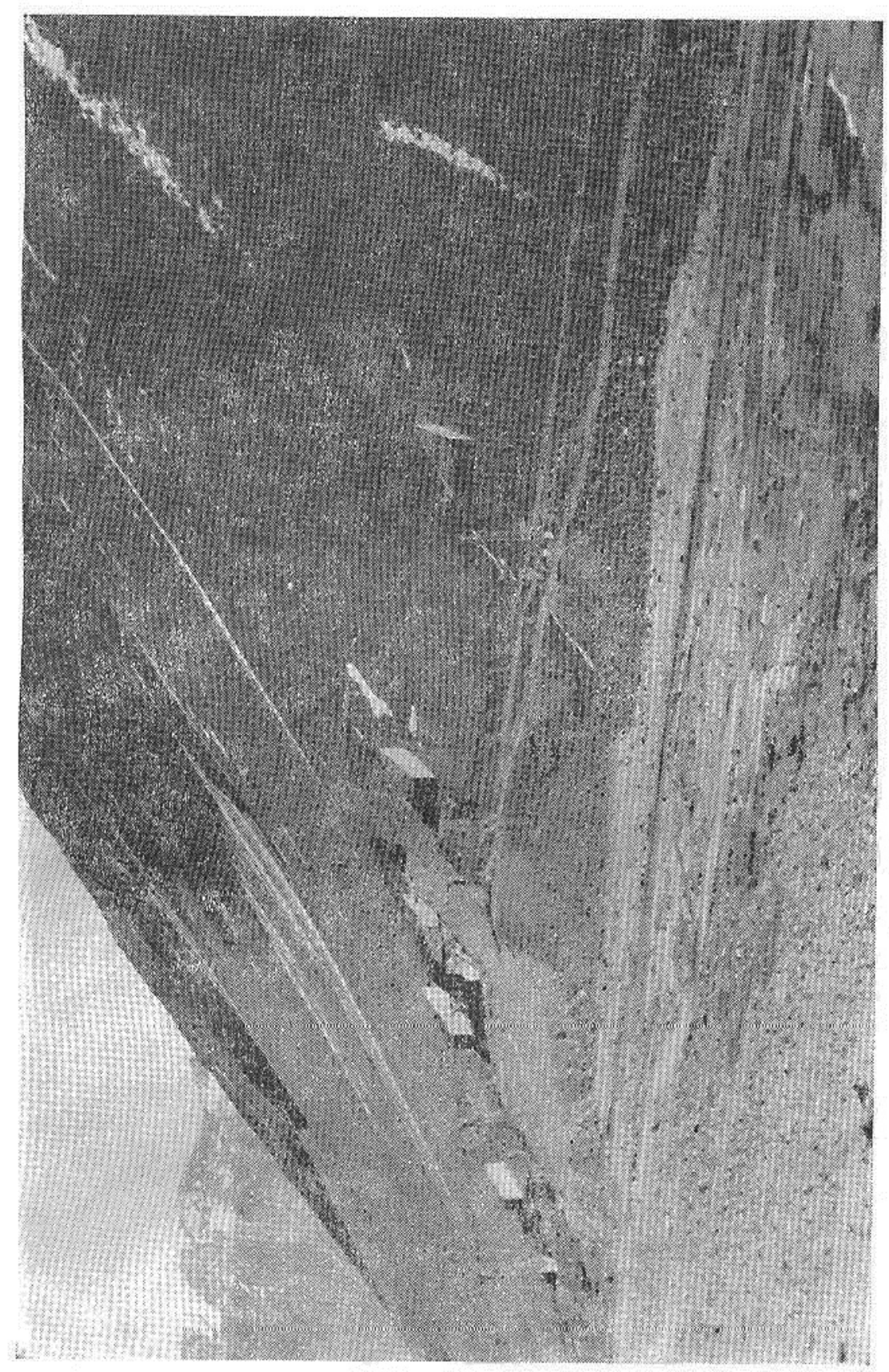

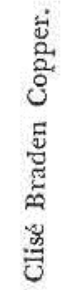




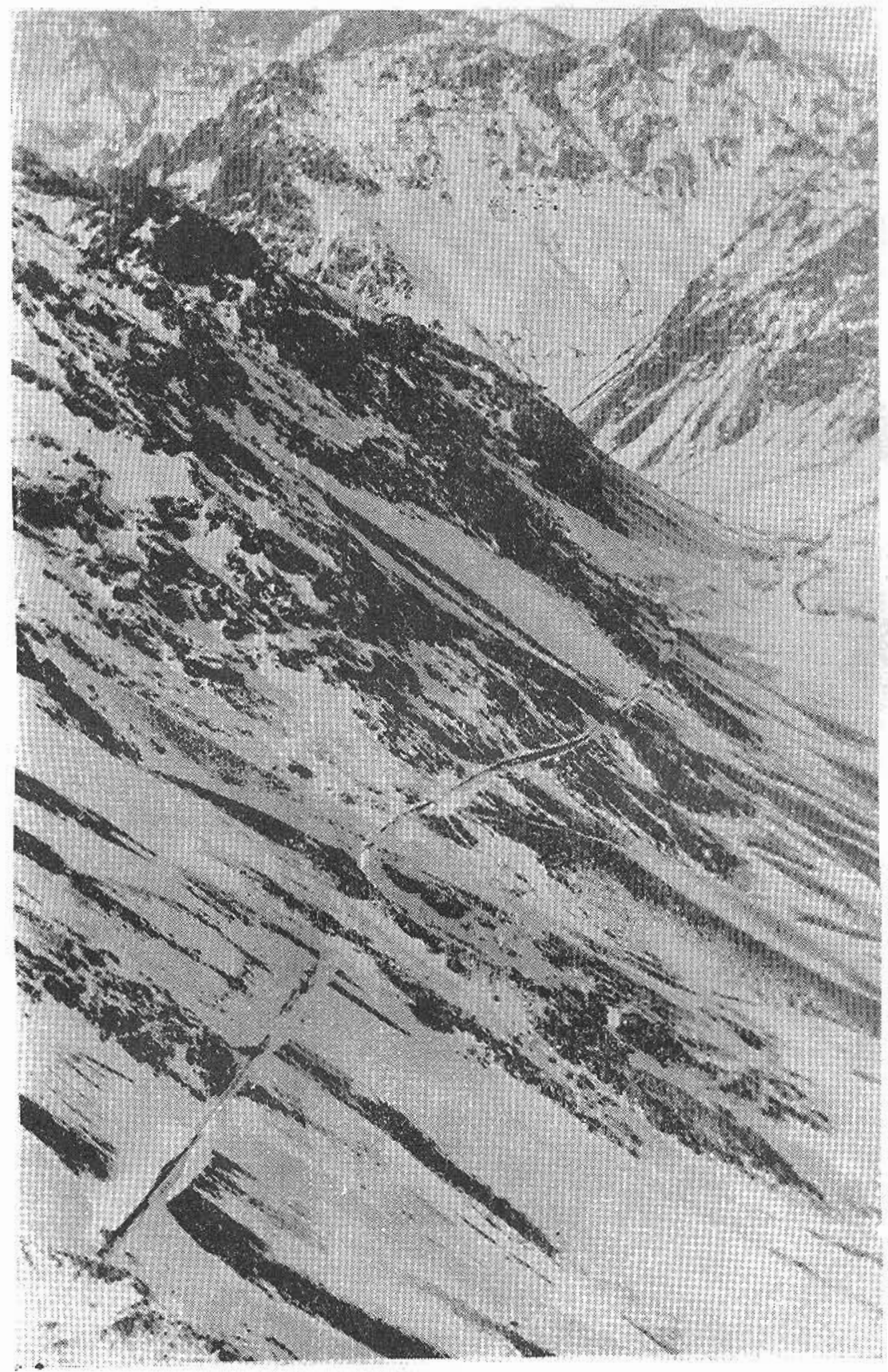

Fig. 7. Ferrocarril internacional. Alto valle del río Aconcagua. 
servicio estaba el experimentado especialista norteamericano M. M. Atwater. Componían además el servicio, oficiales del Ejército de Chile (meteorólogos, artilleros, etc.); el jefe de la Patrulla de Ski de Portillo; el jefe del Andarivel de Portillo y otros. En total, la organización reunía aproximadamente 50 personas. El jefe del Control de Avalanchas tenfa autoridad absoluta para cerrar cualquiera zona o instalación de Portillo. Al comenzar el peligro de avalancha, la artillería efertuaba disparos en todas las rutas de avalanchas. Durante la tormenta del 20 al 22 de julio los artilleros efectuaron disparos con intervalos de cuatro horas. Los resultados fueron muy satisfactorios: se produjeron varias avalanchas, pero ninguna de tamaño destructor. El servicio cumplió con sus deberes enteramente.

\section{El DOMINIO DEL GLIMA TEMPLADO húMEdo CON RELIEVE MEDIANAMENTE DESMEMBRADO}

Este sector coincide en general con la región geográfica del sur de Chile. Tiene precipitaciones abundantes y temperaturas menores en comparación con las dos regiones anteriores. Estas características podrian condicionar una importante actividad de las avalanchas en la región, si las alturas de la montaña no se hubiesen degradado considerablemente.

La breve descripción climática que damos de la región se basa en los datos obtenidos en el sector adyacente en la Laguna del Laja. El autor tuvo oportunidad de visitar csta zona gracias a una amable invitación de ENDESA con el objeto de evaluar el peligro de avalanchas.

\section{a) Las precipitaciones.}

En la región estudiada las precipitaciones son considerables. Ellas aumentan de norte a sur, de 1.000 a $2.500 \mathrm{~mm}$. anuales en la zona premontañosa. La mayoría de estas precipitaciones caen en invierno, lo que favorece la formación de avalanchas. Por ejemplo, en Los Angeles el promedio anual de 40 años de observaciones es de $1.300 \mathrm{~mm}$. de precipitación, de los cuales, el $58 \%$ cae entre junio y septiembre, meses de nevadas en las montañas. Los Angeles está a una altura de $160 \mathrm{~m}$., lo cual hace suponer que en las montañas de la zona las precipitaciones anuales deben ser del orden de $2.000 \mathrm{~mm}$. o más. Por lo tanto, la suma de las precipitaciones invernales deben ser de $1.200 \mathrm{~mm}$. aproximadamente.

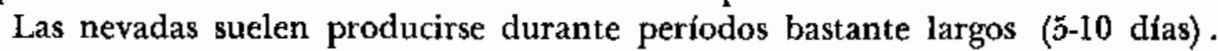
Por ejemplo, en junio-septiembre de 1963, en la zona del desagüe del Lago Laja hubo 5 períodos de precipitaciones cuya duración osciló entre 5 y 12 días. Estos 5 períodos reunieron más del $70 \%$ de las precipitaciones del lapso mencionado. El más prolongado duró 9 días, durante los cuales cayeron $340 \mathrm{~mm}$. Estas grandes nevazones, características para las alturas de más de $1.000 \mathrm{~m}$., son factores muy importantes en la formación de avalanchas.

Los datos de 10 años (1957-66) de las rutas de nieve en la meseta El Toro, 
situada sobre el desagüe del Lago Laja, a una altura de $1.500 \mathrm{~m}$. aproximadamente, muestran que el equivalente liquido de la capa de nieve en promedio es mayor en septiembre e igual a $920 \mathrm{~mm}$. Su densidad es de $0,49 \mathrm{gr} / \mathrm{cm}^{3}$, lo que da una profundidad de la nieve cercana a dos metros. En las hoyas de acumulación de avalanchas esta profundidad debe ser mucho mayor.

Las zonas de acumulación de avalanchas situadas $1.500-2.000 \mathrm{~m}$. de altura sufren rápidas transformaciones porque la nieve fresca es modificada por la temperatura del aire. Los datos de temperatura del aire en el desagüe del Lago Laja muestran que sólo uno de cada 5 dras de los meses invernales tiene temperaturas bajo cero grado. En los otros 25-26 días la temperatura se mantiene siempre sobre cero grado. Bajo la influencia de la radiación solar y las altas temperaturas del aire, la nieve nueva gana rápidamente en densidad, alcanzando pronto valores de $0,4-0,5 \mathrm{gr} / \mathrm{cm}^{3}$.

La nieve fresca, que tiene en general densidacles de $0,1-0,2 \mathrm{gr} / \mathrm{cm}^{3}$, cae sobre la superficie de nieve más densa y puede deslizarse sobre ella a causa de su peso y poca frícción. El peligro de avalanchas de nieve fresca húmeda permanece enton. ces durante la nevada y unos dlas después de ella.

Durante los deshielos de invierno o de primavera, la nieve puede empaparse y deslizar hacia abajo toda la capa de la zona de acumulación, produciendo las avalanchas de fondo mojadas. Suponemos que son éstas las dos causas principales de la caída de avalanchas en la región estudiada. Las otras causas que existen en la naturaleza podrían ocurrir, pero en raras ocasiones.

\section{b) Las áreas de avalancha.}

Por sus condiciones orográficas y su peligro potencial de avalanchas la región puede ser dividida en dos sectores: el septentrional, donde se mantiene todavía la cordillera unida y maciza, con alturas considerables, y el meridional, donde las montañas son de modesta altura sobre las que se yerguen conos volcánicos aislados.

En el sector septentrional, la altura del relieve puede alcanzar $1.000 \mathrm{~m}$. de altura media y las pendientes de las laderas son cercanas a $30^{\circ}$. Los embudos de denudación y los circos glaciales, sectores aptos para la acumulación de nieve y formación de avalanchas, se encuentran en $1.500-2.000 \mathrm{~m}$. de altura, tienen reducidas dimensiones y disminuyen hacia el sur.

En el sector meridional, las alturas e inclinaciones del relieve se reducen a los conos de volcanes. Sólo ellos representan peligro de avalanchas.

\section{c) La vegetación.}

Hasta la altura de $1.000-1.500 \mathrm{~m}$. las laderas están cubiertas de bosque vigoroso, a veces casi impenetrable. Ellos sirven como barrexa contra las avalanchas, reduciendo al mínimo su influencia a pesar de las favorables condiciones climá- 
ticas invernales. Por esto su preservación nos parece fundamental. El grado del peligro de avalanchas en el sector septentrional es mediano o escaso, y nulo en el meridional a excepción de los conos volcánicos.

d) El sector del Lago Laja.

El sector adyacente a las instalaciones de ENDESA presenta poco peligro gracias a las giandes superficies boscosas. La amenaza existe solamente en el camino de Puerto Nuevo al pique que sirve para captar las aguas del Laja. Este corto tramo del camino cruza tres quebradas de avalanchas que funcionan frecuentemente. Como este camino es de poca importancia no vale la pena construir defensa alguna, pero sería conveniente tratar de disminuir el tránsito por él y cerrarlo durante los períodos de crisis.

El mayor peligro de avalanchas existe en la población y en el camino en las orillas de la bahía de los Machos del Lago Laja. En Ia bahia de Los Machos se encuentran: la captación de agua para la planta El Toro (en construcción), la población de los constructores y el camino que conecta estas dos instalaciones. Aunque la ventana del pique está fuera de peligro, el lado meridional puede verse afectado por avalanchas pequeñas.

La mayor parte de la población se encuentra en la orilla occidental de la bahía y sólo algunos edificios están en el sector opuesto. Estos últimos están en la zona de peligro porque alli se reúnen condiciones particularmente favorables a las avalanchas: gran cantidad de nieve, poca vegetación y pendientes fuertes. Los aludes cafdos en el invierno de 1966, que alcanzaron dichas construcciones, confirman lo expresado.

Del análisis del esquema de avalanchas en la zona de población hecho en base a fotografías aéreas se desprende que la ladera occidental esté disectada por quebradas de varios tamaños, cuyas partes superiores sirven como hoyas de acumulación de la nieve de aludes. Las inferiores funcionan como canales de transporte de la nieve hacia la población.

La quebrada principal tiene forma de una depresión que separa las hoyas menores de la divisoria de las aguas. El perfil de la quebrada se presenta en el dibujo (Fig. 8). Se ven cinco partes principales: 1) pendiente suave donde está la población; 2) pendiente fuerte; 3) pendiente muy suave en el fondo de la hoya misma; 4) pendiente fuerte; 5) pendiente suave de Ia meseta divisoria. La inclinación promedio es cercana a $30^{\circ}$, la más favorable para la producción de aludes. En períodos de nevadas débiles esta quebrada no presentará gran peligro porque la nieve deslizada clesde la 'parte superior quedará detenida en la parte plana del fondo de la hoya. Pero en los períodos de abundancia de la nieve, como ocurre en algunos inviernos, se puede temer grandes avalanchas. Las otras cuatro quebradas menores, que tienen pendientes más fuertes deben producir inevitablemente uno o varios rodados cada invierno. El volumen de las avalanchas des- 


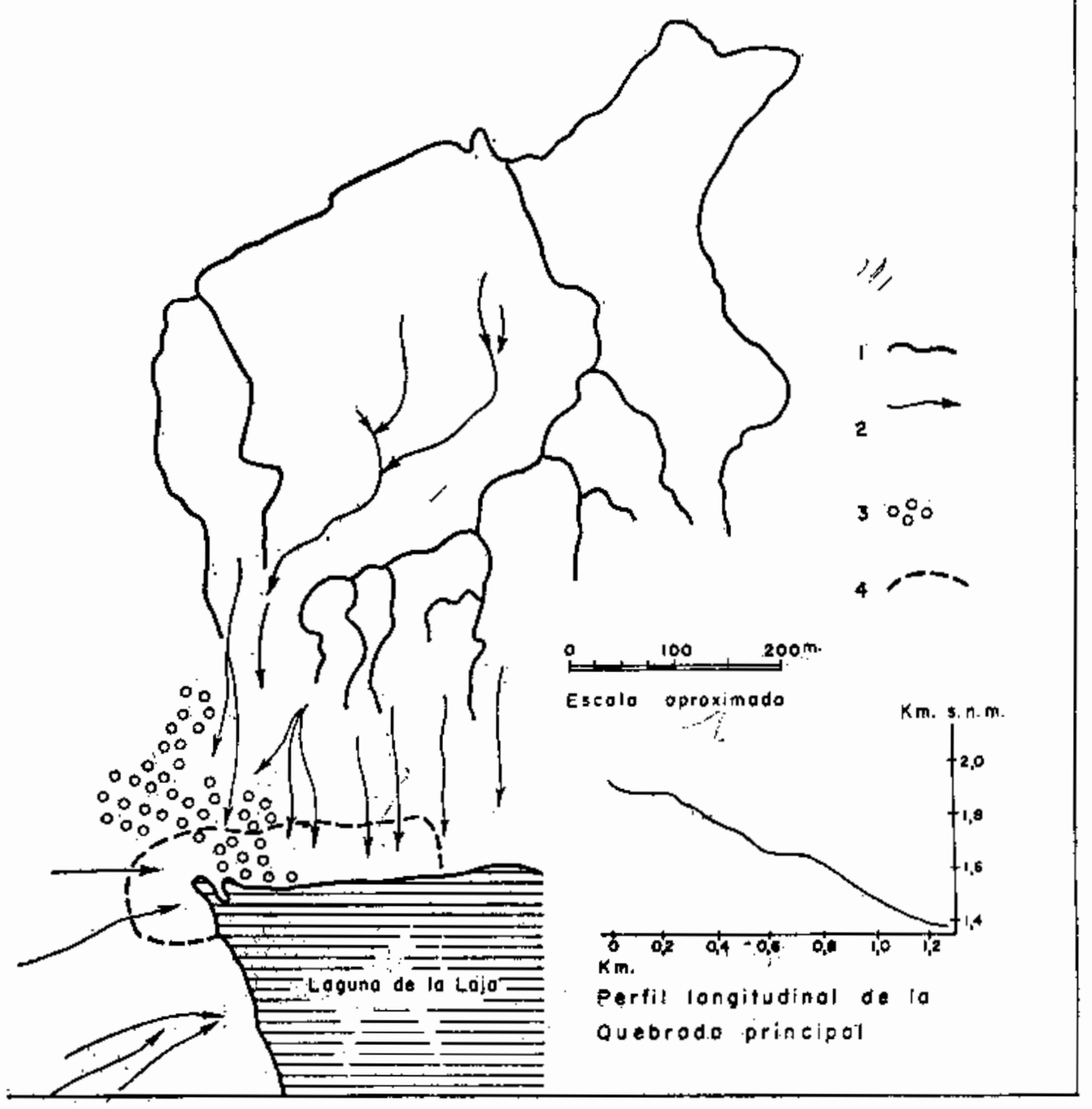

Fig. 8. Esquema de las avalanchas en los machos.

1) Líneas divisorias de cuencas; 2) Rutas de avalanchas; 3) Bosque inferior; 4) Limite aproximádo de la población Los Machos. 


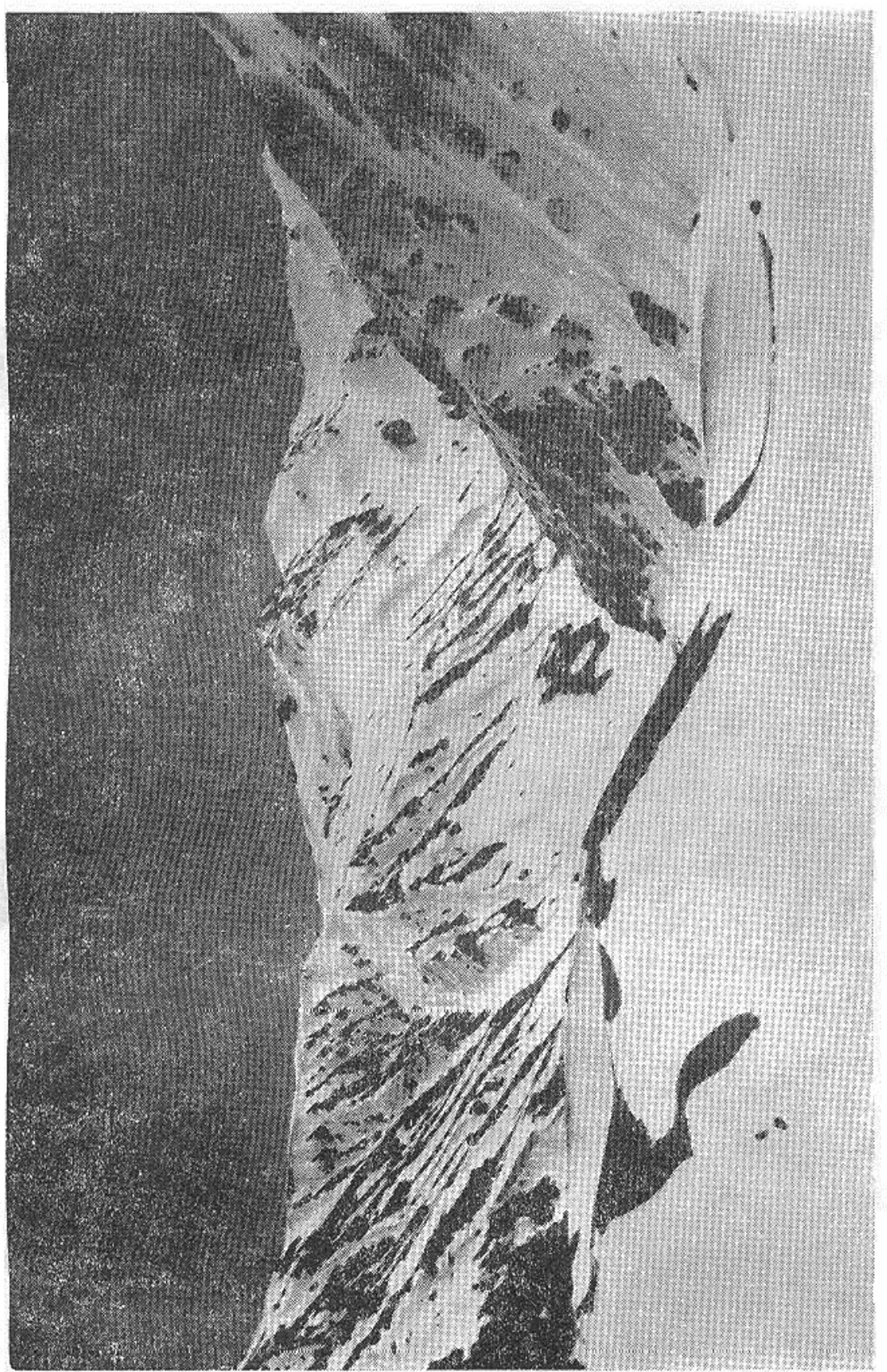

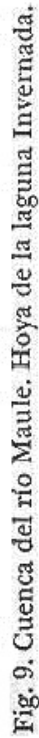




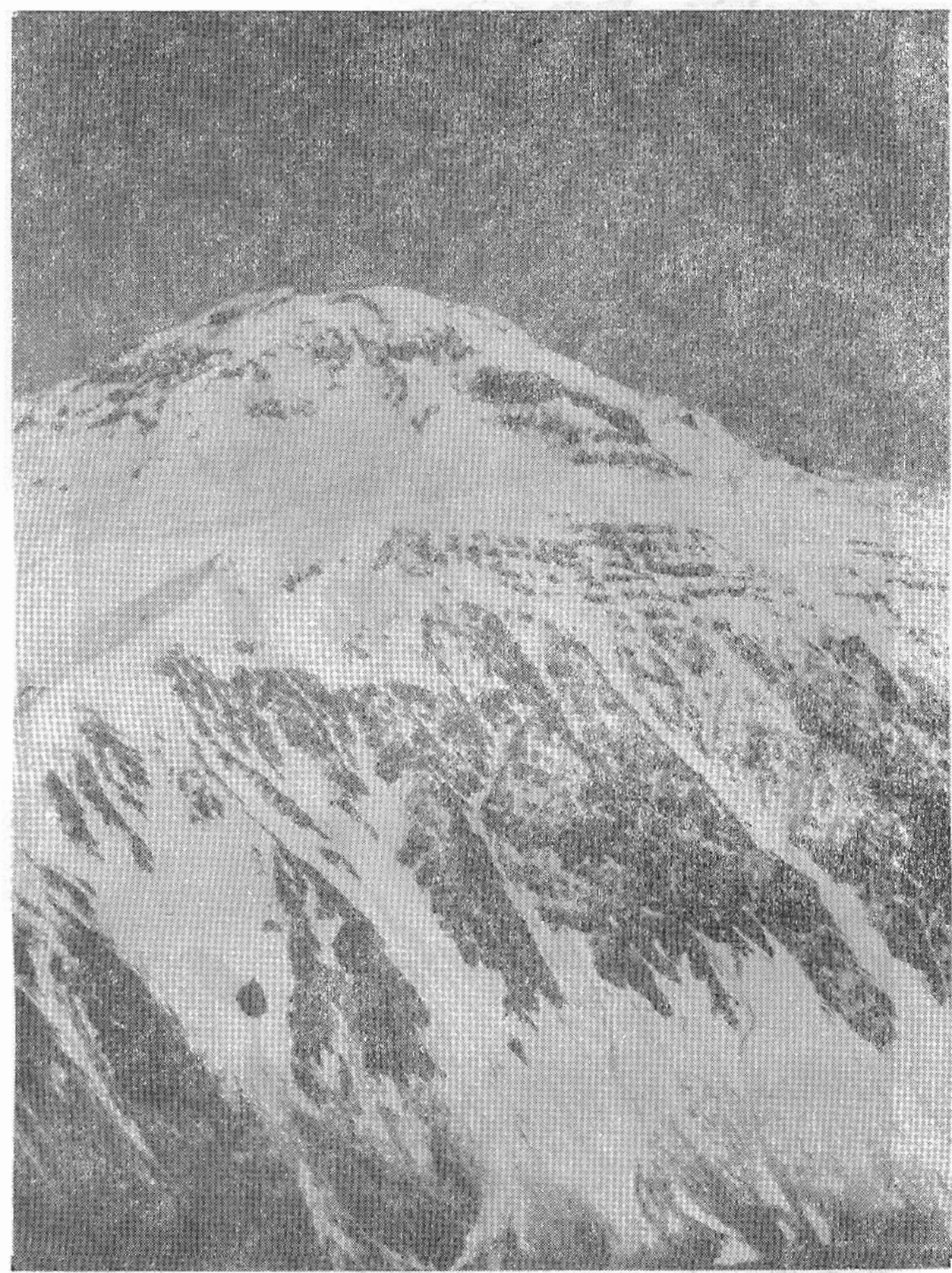

Fig. 10. Rodados de nieve fresca sobre laderas de fucrte pendiente. 
lizadas en estas quebradas puede alcanzar $10.000 \mathrm{~m}^{3}$ o tal vez más, es decir, 40.000 50.000 toneladas de nieve.

En la parte meridional de la población, justamente sobre la maestranza existen dos canales de avalancha. Una de ellas alcanzó esta construcción en agosto del invierno de 1966. Estas laderas pueden tener menos nieve que las otras debido a su exposición. Pero, en cambio, tienen grandes cuencas de acumulación y relieve favorable al movimiento del alud.

El camino entre la población y el pique intercepta en cuatro o cinco lugares canales de avalancha.

En conclusión, en numerosos sectores de Los Machos los aludes amenazan vidas y construcciones, razón que nos impulsó a proponer a la administración de ENDESA, medidas de control de avalanchas, o la creación del servicio de seguridad contra ellas, como las que existen en la URss, EE. uU., los paises de Europa e incluso en Chile.

Además de la zona del Lago Laja, pudimos observar muchas avalanchas en el límite norte de la región, en la cuenca del río Maule y particularmente en la hoya de la laguna Invernada, aguas arriba de la planta hidroeléctrica de Cipreses (Fig. 9). Esta zona está deshabitada y el peligro es entonces sólo potencial.

\section{E. EL DOMINIO DE CLIMA OCEÁNICO FRÍ Y HÚMEDO CON DESMEMBRAMIENTO MEDIO Y FUERTE DEL RELIEVE}

Este sector coincide con el extremo sur de Chile (Patagonia). Se caracteriza por tener precipitaciones muy altas que en la montaña alcanzan probablemente, $5.000 \mathrm{~mm}$. El invierno suave, sin fríos intensos, debe condicionar el desarrollo de una capa de nieve apisonada que, a su vez, produce rodados de nieve fresca húmeda o aludes de fondo mojados (lo que es típico también para las regiones antes mencionadas) ( (Fig. 10) .

La acción de una importante erosión glacial ha generado un relieve de pendientes fuertes que favorece la actividad de las avalanchas.

Al sur de la región, a medida que disminuye la superficie boscosa y en condiciones de relieve favorable, la actividad de las avalanchas debería aumentar. Sin embargo, no existen antecedentes fidedignos de avalanchas en la región. Se sabe por la prensa que el 10 de julio de 1966, a las 9 de la mañana, en el valle de California, hoya del ro Palena, cayó un alud de fondo. Su largo era de $5 \mathrm{Km}$. y, su ancho, $1 \mathrm{Km}$. Dicho alud mató a cuatro personas, destruyó casas, sembrados y ganado.

El 24 de octubre dc 1966 clurante un vuelo sobre esa zona, pudimos observar numerosas huellas de avalanchas en la parte norte de la región, en las hoyas de Palena y Aisén. El 27 de ocrubre del mismo año, constatamos huellas de aludes en las laderas de los glaciares de descarga del hielo patagónico Sur (Fig. 11). Pero el extenso territorio del hielo continental no tiene ningún peligro de avalanchas. 


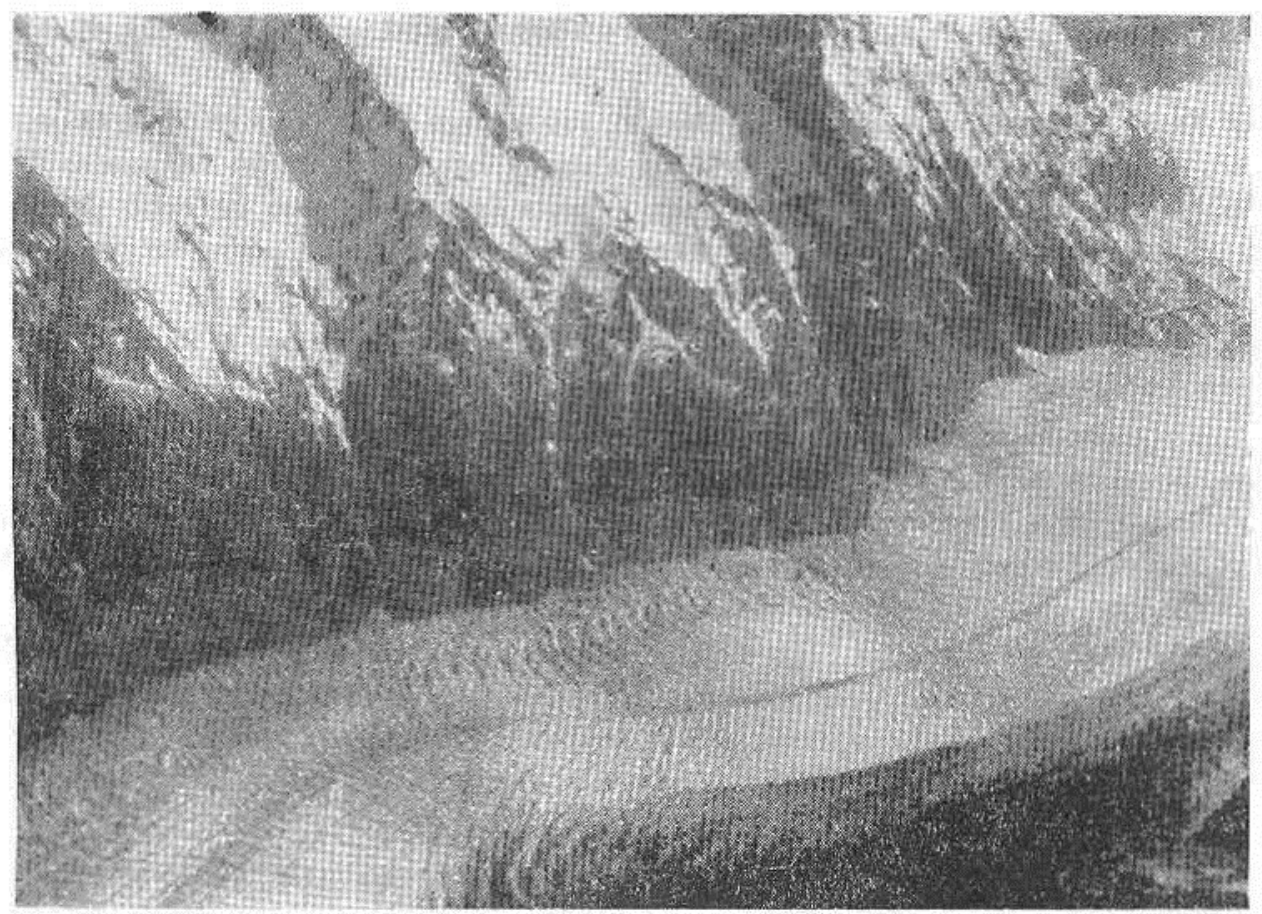

Fig. 11. Glaciar de descarga en cl hiclo patagónico sur.

En conclusión, podemos decir que la alta montaña patagónica es una zona de gran peligro, carácter que será, sin duda, uno de los principales obstáculos para la colonización.

\section{LAS CORRIENTES DE BARRO}

Las corrientes de barro (Mud stream, mud flow, debris flow, en inglés; lave, lave torrentielle, avalanche boueuse, en francés; mure, murgang, ruff, rüffe, en alemán, Diccionario hidrológico, 1966), no son siempre una mezcla de agua y barro. La mezcla puede contener, además, detritos de varios tamaños que van desde cantos rodados a limos finos. El porcentaje de material detrítico puede alcanzar $50 \%$ del volumen total de la corriente. La duración de la corriente de barro es generalmente breve y no sobrepasa sino algunas horas. Hasta ese punto los rasgos de la corriente corresponden a un líquido y su peso volumétrico alcanza $1,8 \mathrm{t} / \mathrm{m}^{3}$. Cuando el porcentaje de detritos supera el $50 \%$, la corriente se hace coherente y se comporta como una masa pegajosa debido a la gran cantidad de partículas de barro que contiene. En este caso el agua no se separa del conjunto cuando la corriente se detiene.

Por su consistencia las corrientes de barro se dividen en dos categorías: las no coherentes, que tienen un movimiento turbulento, y las coherentes, que se mue- 
ven como un cuerpo plástico. Las primeras, a su vez, se dividen en pedregosas, de piedra y barro, y de barro propiamente dicho. En este orden aumenta el peso volumétrico de $1,15 \mathrm{t} / \mathrm{m}^{3}$ a $1,50 \mathrm{t} / \mathrm{m}^{3}$ y más.

Las corrientes de barro pueden transportar piedras de unos cientos de toneladas de peso y su velocidad puede superar los $5 \mathrm{~m} / \mathrm{seg}$., el volumen de piedras acarreadas puede ser de unos millones de metros cúbicos. Por ejemplo, en marzo de 1938 una corriente de barro acarreó a la ciudad de Los Angeles (EE. uU.) más de 10 millones de metros cúbicos de material detrítico. El 8 de julio de 1921, otro proceso semejante desplazó hacia la ciudad de Alma-Ata (URss) \$,6 millones de metros cúbicos. Frecuentemente las corrientes tienen volúmenes que oscilan entre 10 y 100 mil metros cúbicos.

Debido a su gran peso, volumen y velocidad las corrientes de barro poseen una enorme fuerza destructiva. La mayoria se produce en las regiones montañosas, sobre todo en las de clima árido.

Para Ia formación de una corriente de barro se requieren tres condiciones fundamentales:

- La cuenca debe contener mucho material detritico, que constituye la parte sólida de la corriente;

- gran cantidad de agua de liuvia, fusión o vaciado súbito de embalses naturales $o$ artificiales, que forman la parte liquida de la corriente;

- el lecho de la hoya debe tener una inclinación suficiente para asegurar el movimiento de la mezcla.

La falta de una de estas tres condiciones impide la formación de la corriente de barro. Por ejemplo, en el Norte de Chile, las corrientes de barro son raras por falta de agua, al Sur por la carencia de material detrítico y por la importancia de la cubierta arbórea.

Aunque las condiciones necesarias para la formación de corrientes de barro cxisten en muchas partes de la cordillera chilena, éstas se conocen sólo cuando provocan destrucciones considerables. Observaciones sistemáticas de este fenómeno e investigaciones al respecto casi no existen. Como en el caso de las avalanchas, este trabajo representa el primer ensayo para averiguar la distribución de estos fenómenos en el territorio de Chile. Las conclusiones preliminares se basan en observaciones del autor y en el análisis de las condiciones geográficas del país. Con tan precarios elementos, es inevitable que existan lagunas y errores. Rogamos a los lectores tengan a bien indicárnoslos.

Hemos dividido el territorio en regiones de condiciones homogéneas para la formación de las corrientes de barro. La división se hizo en base a observaciones propias y a los siguientes documentos: "Mapa Físico de Chile" escala de 1:1.000.000; "Mapa Geomorfológico de Chile" (1965) de R. Börgel; "Geografía Económica de Chile" corfo (1964) ; E. Lucachova, "América del Sur. Geografía Física" (1961). Además nos basamos esencialmente en el análisis personal de 
las condiciones de alimentación de los ríos chilenos, puesto que el escurrimiento fluvial es un elemento que integra las condiciones naturales del territorio.

Con estos antecedentes tratamos de apreciar la intensidad de los procesos estudiados en distintas regiones, usando como indicadores la cantidad de corrientes de barro por unidad de territorio o su frecuencia estimada para algunos barrancos de la región. El segundo índice es en realidad más preciso y más fácil de apreciar. La experiencia muestra que para una región homogénea estos dos indices deben estar correlacionados directamente. Por eso la frecuencia de las corrientes de barro es también una característica para un territorio estudiado. Consideremos tentativamente que la actividad de las corrientes de barro es alta cuando ellas se suceden por lo menos una vez cada cinco años en algunos barrancos de la región. La intensidad es media cuando la frecuencia varía entre 5 a 15 años y baja cuando es mayor a esta última cifra. Creemos que este indicie permite evaluar cuantitativamente el grado general de peligro en una región. Además dividimos el territorio en regiones de peligro seguro (donde se conocen efectivamente casos de corrientes de barro) y regiones de peligro probable (cuando así lo indica el análisis de las condiciones naturales).

Antes de empezar la descripción de las regiones debemos añadir que no hay que confundir las corrientes de barro que pasan por los lechos de rios y quebradas, con Ios derrumbes y deslizamientos de terreno que ocurren en las laderas. En la formación de estos últimos el agua tiene sólo un papel accesorio. Además, es posible que en una localidad determinada, debido a condiciones naturales muy específicas puedan formarse corrientes de barro singulares que el análisis geográfico no hace esperar.

\section{A. La Cordillera de los Andes de $17^{\circ}$ a $23^{\circ} \mathrm{S}$.}

Situada en el área de clima tropical desértico-montañoso, carece de escurrimiento constante al océano. El relieve está mediano o reducidamente desmembrado y la ausencia de vegetación es casi completa.

Esta región se distingue por la gran cantidád de detritos que se encuentran acumulados en las laderas y en los lechos de las quebradas. Esta acumulación resulta de la intensa intemperización física de las rocas bajo la acción de un clima extremadamente desértico y de la permanencia in situ de los detritos por falta de escurrimiento. La sequedad del clima impide el desarrollo de la vegetación hasta alturas cercanas a los $3.000 \mathrm{~m}$. Estas dos condiciones favorecen la formación de corrientes de barro. Sobre la altura mencionada la hierba reduce la erosión del suelo e impide casi totalmente la actividad de dichas corrientes. Además en esta zona son típicas las rocas volcánicas de gran permeabilidad, de manera que el agua caída se infiltra en su mayor parte.

La actividad de las corrientes de barro está restringuida por los débiles desniveles de la montaña. A pesar de la existencia de alturas de 6.000 y más metros, la montaña tiene contornos suaves debido a la amplia distribución de las rocas 
efusivas y la imposibilidad de erosión. Las mayores inclinaciones se encuentran en la zona de transición entre las sierras y las pampas intermontañosas. Es allí donde se producen corrientes de barro.

El límite inferior de las corrientes de barro son las pampas que están entre la Cordillera de los Andes y la de la Costa. La mayor es la Pampa del Tamarugal limitada al Este por enormes conos de deyección situados entre 1.200 y $1.500 \mathrm{~m}$. de altura.

Asf, en la zona que se ubica entre $\operatorname{los} 1.500$ y $9.000 \mathrm{~m}$. se encuentran abundantes detritos no fijados por la vegetación, hecho que se combina localmente con áreas de considerable inclinación. Es decir, existen estas dos condiciones favorables a la formación de las corrientes de barro, siendo la ausencia del agua la condición limitativa del fenómeno.

Las precipitaciones intensas, que llevan a la formación de las corrientes de barro, soll raras. Su frecuencia y cantidad disminuye del Norte al Sur. La actividad de las corrientes de barro se amortigua en esia misma dirección.

Se sabe de corrientes de barro en la zona de la Pampa del Tamarugal. Ellas pasan por las quebradas que cortan la ladera occidental de la Cordillera de los Andes y depositan sus matcriales de acarreo en los conos de deyección ya mencionados. Eventualnicnte estas corrientes cle barro pueden llegar hasta los salares de la parte central de la Pámpa. Según O. Castillo (1960) una corriente de este tipo pasó por la quebrada de Tarapacá en el mes de marzo de $1981.150 \mathrm{~mm}$. de precipitaciones, caidas durante 10 dias en Chusmiza (2.500 m s.n.m.), produjeron el escurrimiento por la quebrada de un volumen total de diez millones de metros cúbicos. Pero se desconoce el contenido de sedimentos de la crecida. En Pachica el 6 de febrero de 1932 pasó una corriente cuya muestra de agua dio un 22,5\% de sedimentos. Por lo visto, en lit mayoría de los casos estas corrientes son una transición entre crecidas con gran cantidad de sedimentos y corrientes de barro.

Las lluvias y, por lo tanto, las corrientes de barro, se producen en la región estudiada durante el estío, especialmente en los meses de diciembre a febrero. Los límites aproximados de la zona de peligro son Ios siguientes: al Norte la frontera con el Perú, al Este la línea de alturas que marca aproximadamente la curva de $3.000 \mathrm{~m}$. El límite meridional se ubica aproximadamente a $23^{\circ}$ de latitud sur, donde desaparecen las precipitaciones estivales; el lfmite occidental coincide con las bases locales de erosión de las pampas intermontanas (Tamarugal, Llano de la Paciencia, etc.). Es ésta la única región de Chile septentrional y Central donde las corrientes de barro se presentan en verano. Su grado de peligrosidad es innegable pero de baja intensidad.

Debido a la suavidad de las pendiences, a la existencia de una escasa cubierta vegetal y a la permeabilidad de las rocas volcánicas, la zona situada sobre los $\mathbf{3 . 0 0 0}$ m., incluido el Altiplano, no parece peligrosa a pesar de existir allí mayores precipitaciones. 


\section{B. La Cordillera de la Costa entre 20 y $27^{\circ} \mathrm{S}$.}

Este sector tiene un clima tropical desértico, relieve regularmente desmembrado, ausencia de escurrimiento superficial y de vegetacion.

La importancia de las acumulaciones detríticas y la inclinación de las pendientes occidentales de la Cordillera de la Costa hacen suponer una alta posibilidad de corrientes de barro. Pero la ausencia de lluvias intensas inhibe totalmente este peligro. Recordemos, sin embargo, que justamente debajo de laderas potencialmente peligrosas, están los principales puertos del Norte Grande, como Antofagasta, Iquique, Tocapilla, etc.

En resumen, esta región la podemos considerar como de peligro probable y de baja intensidad. Las corrientes de barro se generan en invierno.

\section{La Cordillera de los ANdes y Sierras occidentales ADYACENTES ENTRE 23 Y $27^{\circ} \mathrm{S}$.}

Es un área de clima tropical desértico-montañoso, de relieve medianamente desmembrado. El escurrimiento superficial y la vegetación son casi inexistentes.

No existe ninguna información sobre las corrientes de barro en esta zona. Abundan los detritos, pero las lluvias son muy raras. En Ia parte austral de la región y en los sectores de mayor altura hay más cantidad de precipitaciones. En Potrerillos $(2.850 \mathrm{~m}$. s.n.m.) se registran $61,8 \mathrm{~mm}$. de precipitaciones que se presentan fundamentalmente en invierno. Fs dable suponer que algunos aguaceros puedan llevar a la formación de estas corrientes. En cl período comprendido entre 1927-1945 el máximo absoluto diario registrado en Potrerillos fue de $114 \mathrm{~mm}$. Puede estimarse a la región como de peligro probable con baja intensidad.

\section{La Cordillera jet. Norte Chico entre 27 y $33^{\circ} \mathrm{S}$.}

Domina allí el clima subtropical con rasgos semidesérticos. El relieve se presenta mediano o fuertemente disectado. Los ríos se caracterizan por su alimentación nivo-pluvial. Lá vegetación es semidesértica y esteparia.

La aridez del clima determina una intensa intemperización de las rocas y, por lo tanto, abundante material suelto, que las precipitaciones no consiguen evacuar. La vegetación es dispersa, lo que favorece también la formación de corrientes de barro. Las inclinaciones son considerables. Se presentan precipitaciones todos los años en el invierno y aun en las zonas de poca altura, alcanzando $300 \mathrm{~mm}$. por año, en el sector meridional. Todos estos antecedentes convierten la región en la más peligrosa de todo Chile, por la alta intensidad de las corrientes de barro.

Tuvimos la posibilidad de visitar varias veces la región y la descripción que sigue es el fruto de nuestras observaciones.

En el valle del Elqui, las laderas casi no tienen vegetación sobre $l o s 1.000 \mathrm{~m}$. Ẹn esta parte del valle existen numerosos conos de deyección de antiguas corrientes 
de barro - su longitud puede alcanzar $500 \mathrm{~m}$. a lo largo del río y su espesor hasta $20 \mathrm{~m}$. En ellos se inscriben ahora los lechos de los afluentes del Elqui. Los conos de las corrientes de barro actuales se inscriben parcialmente en las anteriores y por otra parte progresan hacia el rio. Sus volúmenes son mucho menores en comparación con los antiguos. Pueden alcanzar $10.000 \mathrm{~m}^{3}$ aproximadamente. Están formatlas en su mayor parte de piedra o de piedra y barro.

Sobre cierta aItura, las precipitaciones invernales caen solamente en forma de nieve. Ellas determinan el límite superior de las corrientes de barro. En la hoya del Elqui este límite está a $2.200 \mathrm{~m}$. de altura aproximadamente.

En el valle del Limari el límite inferior desciende hasta $500-600 \mathrm{~m}$. y el superior se encuentra entre 2.200 y $2.500 \mathrm{~m}$. En la hoya del Limari pudimos observar en todos los rios que visitamos (Grande, Los Molles, Salala) huellas de corrientes de barro producidas todas ellas en invierno (junio-agosto). Predominan las de piedra y las de piedra y barro. La quebrada Huracán, situada a unos cientos de metros aguas arriba de la planta hidroeléctrica de Los Molles, en el borde derecho del río del mismo nombre, nos permitirá describir una quebrada típica en que se producen corrientes de barro (Fig. 12). La hoya de la quebrada se divide en cuatro partes:

1) La superior se sitúa entre 3.000 y $2.500 \mathrm{~m}$. aproximadamente. No existe alli manifestación de corrientes de barro. El embudo superior está cortado por barrancos con inclinaciones de hasta $45^{\circ}$ que sirven de vías de avalancha. En la superficie afloran rocas desnudas, toda la roca meteorizada se desplaza hacia aguas abajo.

2) La zona de formación de las corrientes de barro se encuentra entre los 2.500 y $2.100 \mathrm{~m}$. aproximadamente. Está formada principalmente por depósitos desplazados desde la zona superior. En los cuales se desarrolla un barranco de erosión de $50 \mathrm{~m}$. de profundidad y $100 \mathrm{~m}$. de ancho. La inclinación del lecho es de $30^{\circ}$. Estas cifras son aproximadas, pues nuestras observaciones fueron hechas clesde la ladera opuesta del valle. El barranco tiene un perfil en forma de " $V$ ". Las corrientes de barro se generan a expensas de los materiales arrancados por la erosión a las laderas y al cauce del barranco favorecidos por la ausencia casi total de vegetación.

3) Entre 1.600 y $2.100 \mathrm{~m}$. se encuentra la zona de transporte de las corrientes de barro. La vegetación cubre cerca del 70\% de Ia superficie. El barranco es mucho menor que en la zona anterior, tiene bordes muy abruptos, de $10 \mathrm{~m}$, y más de altura, y lecho plano de unos $20 \mathrm{~m}$. de ancho.

4) Entre 1.600 y $1.500 \mathrm{~m}$. aproximadamente se encuentra la zona de acumulación de las corrientes de barro, que forman conos de piedra y barro.

Una corriente de barro que se produjo el 15 de agosto de 1965, en Ia quebrada de la Vaca Brava destruyó 9 viviendas, el Retén de Carabineros y las caba. llerizas, en la población de la Central Los Molles. El alud ocurrió durante el día, factor que impidió que se produjeran víctimas.

De acuerdo a la información proporcionada por testigos presenciales, la co- 


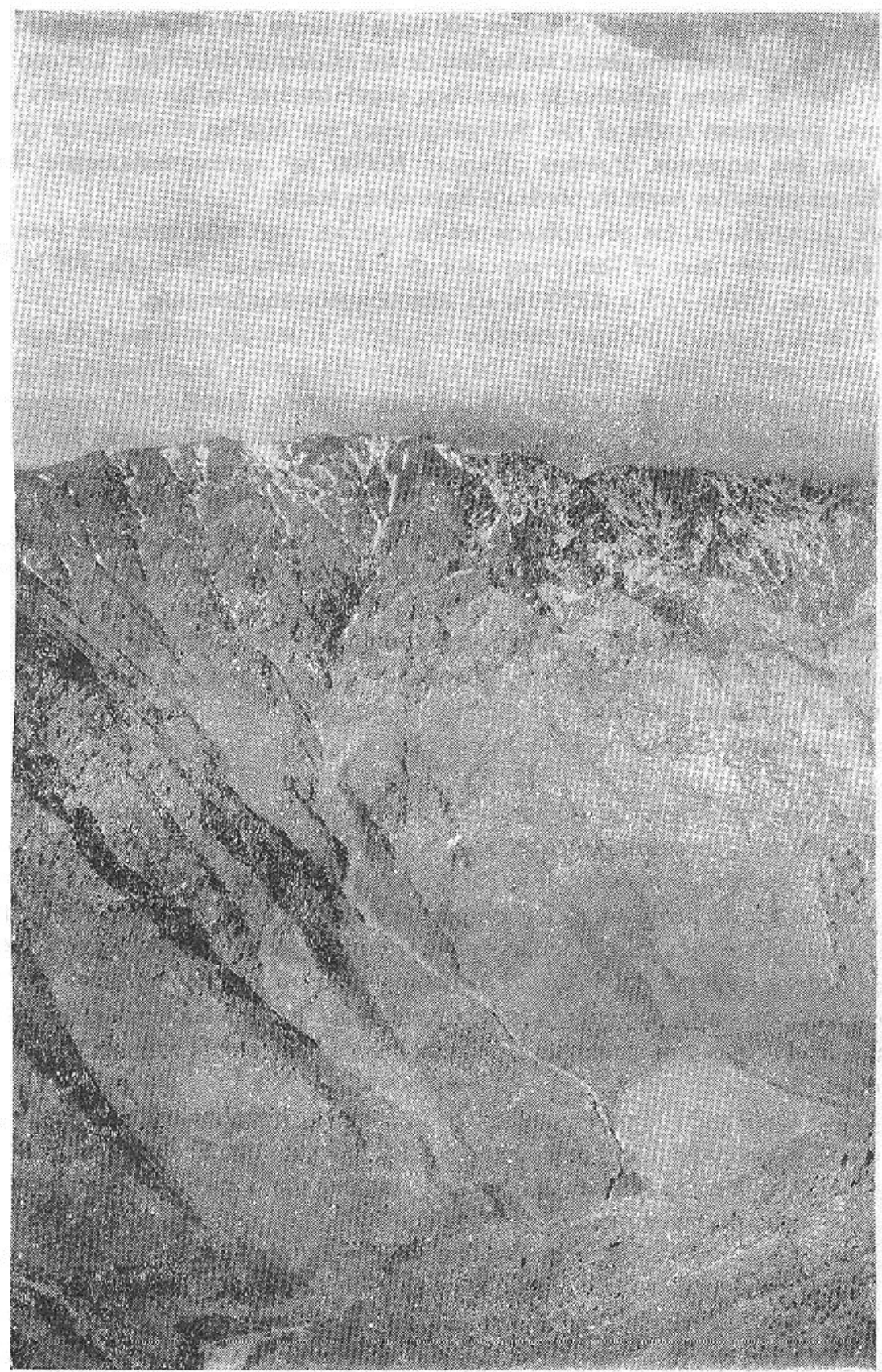

Fig. 12. Valle del Alto Limari. 


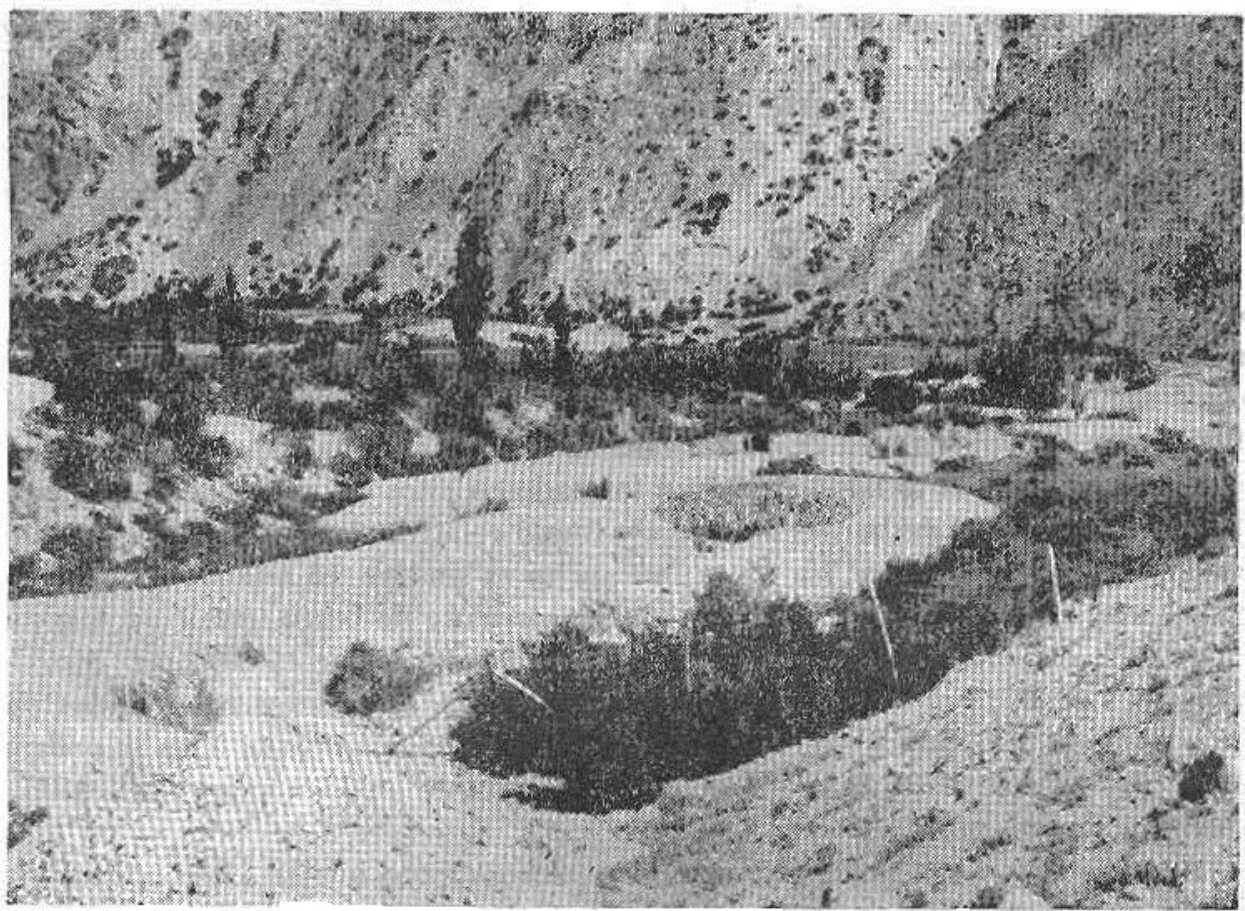

Fig. 13. Corriente de barro. Central Los Molles.

rriente estaba formada por una masa de barro y piedras pequeñas sin escurrimiento de agua libre. El volumen del material sedimentado en la zona de la población se calcula en 100 y $150.000 \mathrm{~m}^{3}$. La masa depositada demoró algunos meses en secarse, lo que traduce un tipo de corriente coherente en que el agua de la masa es absorbida por la arcilla. (Fig. 13) .

La Sección Seguridad de la ENDESA tuvo la gentileza de invitarnos para estudiar este fenómeno, indicar las posibilidades de nuevas corrientes de barro y proponer las posibles medidas de defensa. He aquí nuestras observaciones:

La quebrada Vaca Brava, afluente del río Molles está situada al poniente de la población. Su desembocadura se encuentra a $1.350 \mathrm{~m}$. y su nacimiento a unos $1.700 \mathrm{~m}$. más alto. La longitud de la quebrada es del orden de $3 \mathrm{Km}$., lo que indica unos $30^{\circ}$ de pendiente promedio del cauce. Si descontamos el tramo final de la quebrada, que es relativamente plano por estar situado en el valle del río Molles, el valor de la pendiente aumenta a $40^{\circ}-45^{\circ}$. La superficie de la hoya hasta la defensa actual, la podemos estimar, por mediciones hechas en fotografías aéreas, en unos $2 \mathrm{Km}^{2}$.

La parte occidental de la cuenca está cubierta por sedimentos poblados de escasa vegetación. En los sectores más altos se observa afloramientos de roca fundamental y derrumbes en la base de las laderas. El agua se infiltra en los ma- 
teriales detríticos y escurre hacia el cauce del río por vía subterránea. Por lo tanto, no se observan huellas de corrientes superficiales.

Por el contrario, en la parte izquierda los afloramientos de roca fundamental son de mayor importancia y muy reducida la cantidad de material suelto. La meteorización de estas rocas produce la arcilla fina causante de la corriente de barro.

En la parte central de la quebrada existe un cauce de aproximadamente $2 \mathrm{Km}$. de longitud, de los cuales $1,5 \mathrm{Km}$. está cubierto de rocas sueltas, que son presumiblemente restos de antiguas corrientes de barro. La profundidad visible de estos sedimentos es por lo menos de $20 \mathrm{~m}$. Este cauce colecta las aguas que llegan por vía subterránea desde la parte derecha y por vía superficial desde el costado izquierdo. A lo largo del cauce formado en estos escombros, existe actualmente un barranco de bordes abruptos y fondo relativamente plano. La profundidad del barranco es de 7 a 15 m., su ancho es similar. El análisis de la fotografía aérea muestra que antes de la última corriente de barro, este barranco no existía. El volumen de material que salió del barranco es de $150.000 \mathrm{~m}^{3}$. aproximadamente, cifra que coincide con el volumen de sedimentos acumulados en la población. Si dividiésemos esta cifra en la superficie de toda la hoya se podría decir que ella movilizó una capa de 50 a $100 \mathrm{~mm}$. de espesor, lo que indica una corriente de intensidad muy alta. (Fig. 14).

Aguas arriba de la defensa actual se ven claramente huellas de corrientes de barro anteriores. Allf se acumulaban materiales de las quebradas cuando no existian las condiciones extraordinarias que hicieron pasar hacia el valle la última que se produjo.

Como se ha dicho, para la formación de una corriente de barro tienen que existir tres condiciones principales:

a) Pendientes de gran magnitud; b) gran cantidad de rocas sueltas que pueden ser arrastradas por el agua, y c) volumen de agua suficiente para arrastrar el material. En la quebrada estudiada existen las dos primeras condiciones. En agosto de 1965 se produjo la tercera de ellas.

De acuerdo a la información disponible, a principios de agosto había bastante nieve en la parte superior de la quebrada (la mayor nevada de que tengan recuerdo los habitantes del Iugar se habla producido el 12 de julio anterior). La distribución diaria del agua caida en Los Molles, en el mes indicado, es la que sigue:

\begin{tabular}{lccccccccc}
\hline $\begin{array}{l}\text { Fecha: } \\
\begin{array}{l}\text { Precipita- } \\
\text { ción. mm. }\end{array}\end{array}$ & 9 & 10 & 11 & 12 & 13 & 14 & 15 & 16 & 17 \\
\hline
\end{tabular}

Es decir, en el perfodo comprendido entre el 9 y el 15 de agosto cayeron $162,3 \mathrm{~mm}$. La temperatura del aire en la zona alta con nieve era superior a cero 


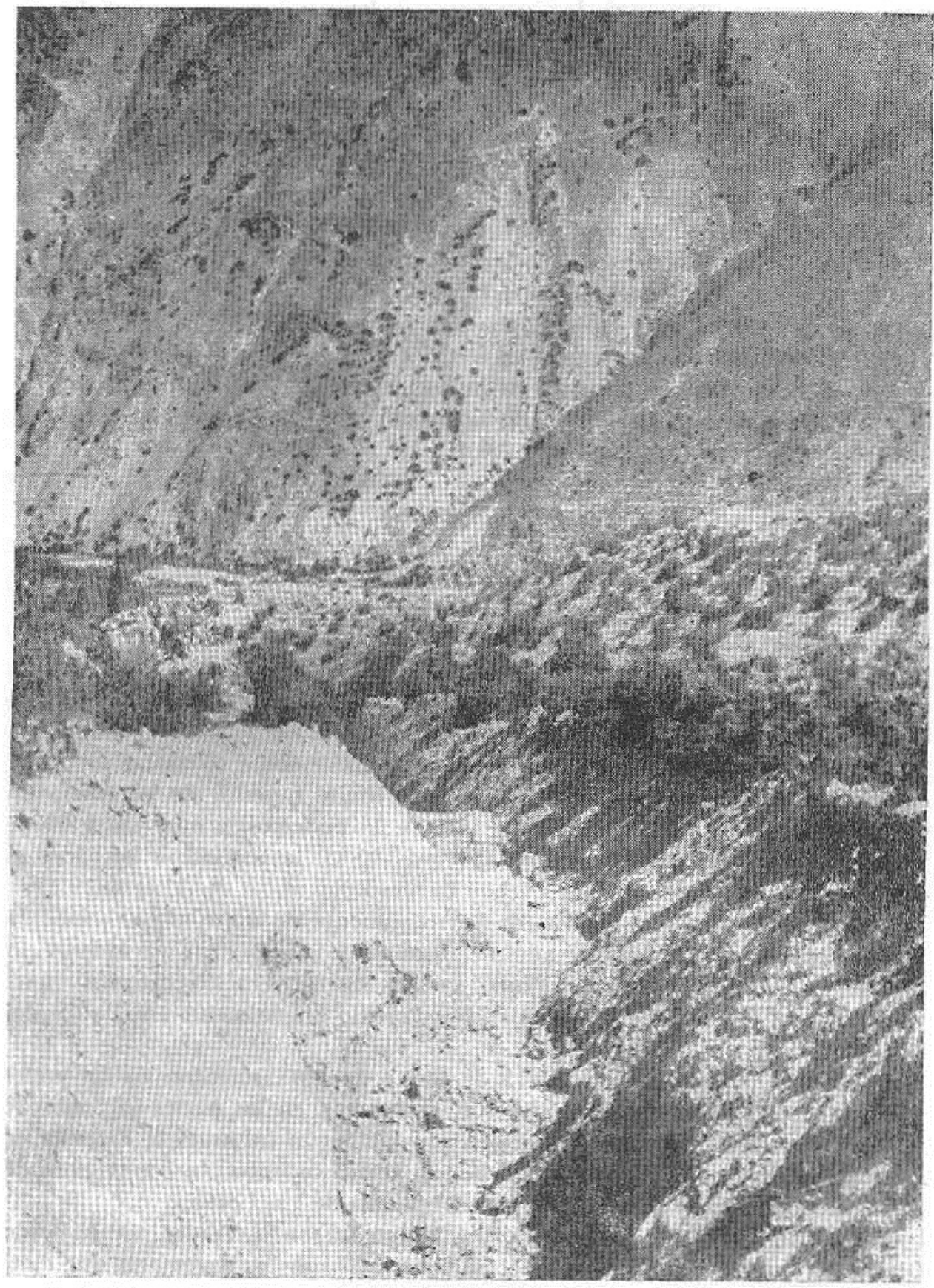

Fig. 14. Quebrada Vaca Brava. Rio Molles, 
grado. La acción colectiva de la lluvia y de la temperatura provocó el derretimiento de la nieve. De ese modo, en la hoya de la quebrada se produjo un escurrimiento considerable proveniente tanto del derretimíento de nieve como de precipitaciones. Esta agua empapó además los materiales detriticos. El equilibrio de dichos materiales fue perturbado $y$ se generaron desprendimientos de tierra que alimentaron la corriente de barro.

Un caso muy parecido sucedió en el Cáucaso en el año 1940, aunque en ese lugar el material que formaba la corriente de barro fue del orden de un millón de metros cúbicos (Corrientes de barro en la urss, 1964). Para proteger la población el lecho de la quebrada fue tapado y su trazado desviado hacia otra quebrada que sale al valle en una zona sin construcciones.

La región estudiada es entonces un sector de peligro seguro y alta intensidad de corrientes de barro, se generan en invierno y tienen origen pluvial o mixto (lluvia y derretimiento de nieve). En la parte central de la zona las corrientes de barro se producen entre 108500 y $2.500 \mathrm{~m}$.

\section{E. La Cordillera de los ANdes ENTRe 33 y $85^{\circ} \mathrm{S}$.}

Es un sector de clima subtropical seco (mediterráneo). El relieve está fuertemente desmembrado, los róos tienen alimentación nivo-glacial y la vegetación caracteristica es el matorraI.

La actividad de las corrientes de barro en este sector, tiene todas las condiciones necesarias para su desarrollo, pero la presencia de una cubierta vegetal más densa hace esta área menos peligrosa que la del Norte Chico. Como ya dijimos anteriormente, entre los 2.500 y $8.000 \mathrm{~m}$. de altura, prácticamente todas las precipitaciones caen en forma de nieve, siendo éste el límite superior de las corrientes de barro de origen pluvial. El límite inferior lo podemos estimar entre $800 \mathrm{y}$ $1.000 \mathrm{~m}$. En la zona situada entre 1.000 y $2.500 \mathrm{~m}$. la vegetación herbácea se complementa con la de arbustos y árboles, en especial al sur de la región.

La intensidad de las corrientes de barro aumenta de norte a sur, a medida que crecen las precipitaciones, aunque disminuya la superficie de laderas sin vegetación. Pudimos observar algunas huellas de corrientes pedregosas en el valle del Aconcagua entre el Río Blanco y Portillo e igualmente en el valle del Mapocho.

Durante la tempestad del 8 al 15 de agosto de 1965, mientras en las partes superiores de la montaña se produjeron avalanchas, en las partes inferiores se generaron corrientes de barro de origen pluvial. Según informes la Patrulla de Esquí de Chile, en el valle del Mapocho-San Francisco hubo cinco corrientes de barro, que cortaron el camino a la mina Disputada de Las Condes.

Las corrientes de barro del valle del Maipo fueron indicadas por J. Borde (1968). Su interpretación de un proceso conectado con los terremotos que desequilibran rocas y rellenos de laderas nos parece muy interesante. Como resultado de ello el máximo de las actividades se presenta después de los temblores y luego 
disminuye gradualmente. J. Borde observó corrientes de barro de origen pluvial al principio y a fines de invierno en las quebradas de la ladera izquierda del río Yeso. Según su descripción se trataba de corrientes coherentes.

Así, prácticamente en todos los valles de la región entre 1.000 y $2.500 \mathrm{~m}$. de altura, se presentan corrientes de barro de origen pluvial. Su intensidad se puede estimar como mediana.

La existencia de ventisqueros en la región permite suponer que deben existir también corrientes de barro de origen glacial. Su formación está favorecida por la abundancia de material morrénico, que bordea los glaciares, y la gran cantidad de agua, que a veces puede procurar eventualmente la alta ablación del hielo y el vaciado de lagunas, etc. (Kusmin, 1961).

Según L. Lliboutry, en esta zona de la Cordillera de los Andes se conocen dos crecidas conectadas con rupturas de lagunas glaciares. Una de ellas en el territorio argentino. La otra, se produjo el año 1954 en el río Olivares debido al vaciado del lago después del avance del glaciar Juncal Sur.

Entonces, se puede considerar la zona periglacial actual como de peligro probable. El límite inferior de la zona peligrosa depende de varios factores, incluso de la morfología de los valles, por eso no es posible hacer un diagnóstico para toda la región.

\section{F. La Cordillera de los ANdes entre 35 y $37^{\circ} \mathrm{S}$.}

Tiene clima subtropical, róos de alimentación nivosa y pluvio-nival, relieve mediano o fuertemente desmembrado y predominio de vegetación forestal.

En este sector ya no existe una estación completamente seca (Lliboutry, 1956). Las precipitaciones en las alturas medias alcanzan a $1.000 \mathrm{~mm}$. La vegetación forestal coloniza la topografía en forma indistinta. Es el borde meridional de la zona geobotánica mesomórfica (CORFo, 1964). Al mismo tiempo el relieve pierde altura y disminuye mucho la superficie de los glaciares. Las corrientes de barro se producen gracias a la presencia de material friable sobre la zona ocupada por el bosque y a una considerable cantidad de precipitaciones. En la hoya del río Maule, observamos muchas huellas de corrientes de barro. Aguas abajo del río Cipreses encontramos tres quebradas en que éstas se producen. La hoya del Cipreses tiene un alto grado de peligrosidad. Una de las quebradas al lado derecho del valle, justamente aguas arriba de la población Cipreses, forma un cono de $0,5 \mathrm{Km}$. de ancho con huellas de frecuentes corrientes de barro. Predominan aquellas formadas de piedra y a veces las de piedra y barro. En la matriz de cieno se encuentran cantos rodados hasta de $1 \mathrm{~m}$. de diámetro. En el tramo comprendido entre la población y la Laguna Invernada, anotamos cinco quebradas que canalizan corrientes de barro. Aguas arriba de la Laguna, en la zona más disectada, ellas se desplazan por casi todas las quebradas.

La zona de alimentación constituye un embudo de fuerte inclinación. En muchos casos, algunos embudos relativamente pequefios se juntan en una hoya. 
Las zonas de tránsito de las corrientes de barro constituyen barrancos de erosión con diques de piedra en los bordes, ocupados por el bosque. Pudimos observar estas quebradas en primavera, a fines de octubre de 1966, cuando las zonas de alimentación y parcialmente las zonas de tránsito, estaban cubiertas de nieve. A pesar de esto podía ver que la mayor parte del volumen de las corrientes de barro proviene de la llamada zona de tránsito. Alli se acumula mucho material friable desplazado desde los sectores más altos. Su desplazamiento es favorecido por la concentración del escurrimiento y la fuerte inclinación de las pendientes.

En este caso, la llamada zona de alimentación sirve como colector de agua e incluso puede no participar en la formación de las corrientes. Cuando las lluvias de julio y agosto producen corrientes de barro, Ia "zona de alimentación" está cubierta con nieve. Pero a veces una parte de la nieve se derrite durante las lluvias y se forman entonces corrientes de barro de origen mixto, pluvio-nival.

En la parte superior de la hoya de Cipreses el relieve cambia radicalmente. Hay alli muchos volcanes apagados que acumularon lavas y cenizas de gran espesor generando un relieve suave y poco contrastado. Gracias a esto, a la gran capacidad de infiltración de las rocas volcánicas y a la debilidad de las precipitaciones líquidas, las corrientes de barro desaparecen.

En resumen, esta región se puede calificar de peligrosa en las áreas donde la altura de las sierras supera el nivel superior del bosque (sobre $2.000 \mathrm{~m}$. aproximadamente). La frecuencia de corrientes de barro es variable en períodos que oscilan entre 5 y 15 años, aunque en algunas quebradas puedan producirse con mayor frecuencia. Las áreas que están entre 1.000 y $2.000 \mathrm{~m}$. son probablemente de peligro de baja intensidad.

\section{G. La Cordillera de los Andes entre 37 y $42^{\circ} \mathrm{S}$.}

Este sector tiene clima subtropical húmedo, rios de alimentación lluviosa o nivo-pluvial, relieve débil o medianamente desmembrada y vegetación de bosques vigorosos.

No se tienen noticias de corrientes de barro. La vegetación de bosques que cubren las laderas, impide su desarrollo, aunque las precipitaciones sean abundantes, del orden de $5.000 \mathrm{~mm}$. por año en la montaña.

Sin embargo, la explotación desmedida del bosque podría cambiar radicalmentela situación.

\section{H. SECTOR COMPRENDIDO ENTRE 42 Y $46^{\circ}$ DE LATITUd SUR.}

Tiene clima templado oceánico y ríos de alimentación principalmente nivopluvial. El relieve ha sido disectado en un grado medio a fuerte y se encuentra cubierto de bosques.

A pesar que no posee grandes alturas (menos de $3.000 \mathrm{~m}$.) muchos valles son profundos $\mathrm{y}$ de considerables pendientes. Las precipitaciones en la montaña 
superan los $5.000 \mathrm{~mm}$. El factor que limita la formación de corrientes de barro es la falta de material detrítico, dichos materiales son constantemente transportados por las lluvias. Las crecidas de agua son típicas siendo uno de los fenómenos más peligrosos. Sin embargo, pudimos observar desde el avión huellas de corrientes de barro en las hoyas de los ríos Palena y Aisén. Son los únicos antecedentes de que disponemos.

La región se puede catalogar como probablemente peligrosa, la ausencia de datos hace imposible evaluar su intensidad.

\section{El. Área montañosa de Chile ar sUR del paralelo $46^{\circ} \mathrm{S}$.}

Posee clima oceánico templado, grandes superficies de glaciares, relieve medianamente disectado y vegetación de bosques.

Las condiciones naturales son semejantes a las de la región anterior y carecemos de antecedentes sobre corrientes de barro de origen pluvial.

Sin embargo, la existencia de grandes glaciares debe favorecer la actividad de las corrientes de barro de origen glacial. L. Lliboutry (1956) indica la existencia de crecidas conectadas al vaciamiento de lagunas glaciales. Tales crecidas transportan mucho material morrénico y en muchos casos tienen el carácter de corrientes de barro. En base a los antecedentes publicados por el autor mencionado más arriba, vamos a presentar algunos ejemplos de crecidas en Patagonia.

El valle del rfo Colonia, afluente del Baker, inunda ocasionalmente su lecho en $600 \mathrm{~m}$. de ancho, debido al vaciado deI Jago Arco - de $4 \mathrm{~km}$. de Iargo- que se encuentra al Iado del glaciar. Lo mismo ocurre, aunque con menor importancia, en los ríos Nef y el afluente que desemboca en el Estrecho de Fernando Lamera.

En el territorio argentino, el glaciar Moreno obtura periódicamente una parte del lago Moreno, provocando un aumento del nivel lacustre. Cuando el dique se destruye, casi siempre en verano, se produce una crecida. Entre 1985 y 1955 , este hecho ha ocurrido por lo menos ocho veces.

Hipotéticamente consideramos la región como probablemente peligrosa, la intensidad de las corrientes de barro de origen pluvial es baja y mediana las de origen glacial.

\section{MAPA ESQUEMATICO DE AVALANCHAS Y CORRIENTES DE BARRO EN CHILE}

El mapa esquemático de avalanchas y corrientes de barro que hemos preparado reúne datos de literatura, observaciones propias y el análisis de las condiciones naturales. La ausencia de datos sobre avalanchas y corrientes de barro nos nos permitió extender la cartografía a la región patagónica. El mapa propuesto es sólo esquemático, pues faltan datos que nos permitan dar por seguro el trazado de los limites establecidos. Sin embargo, este mapa es el primero de 


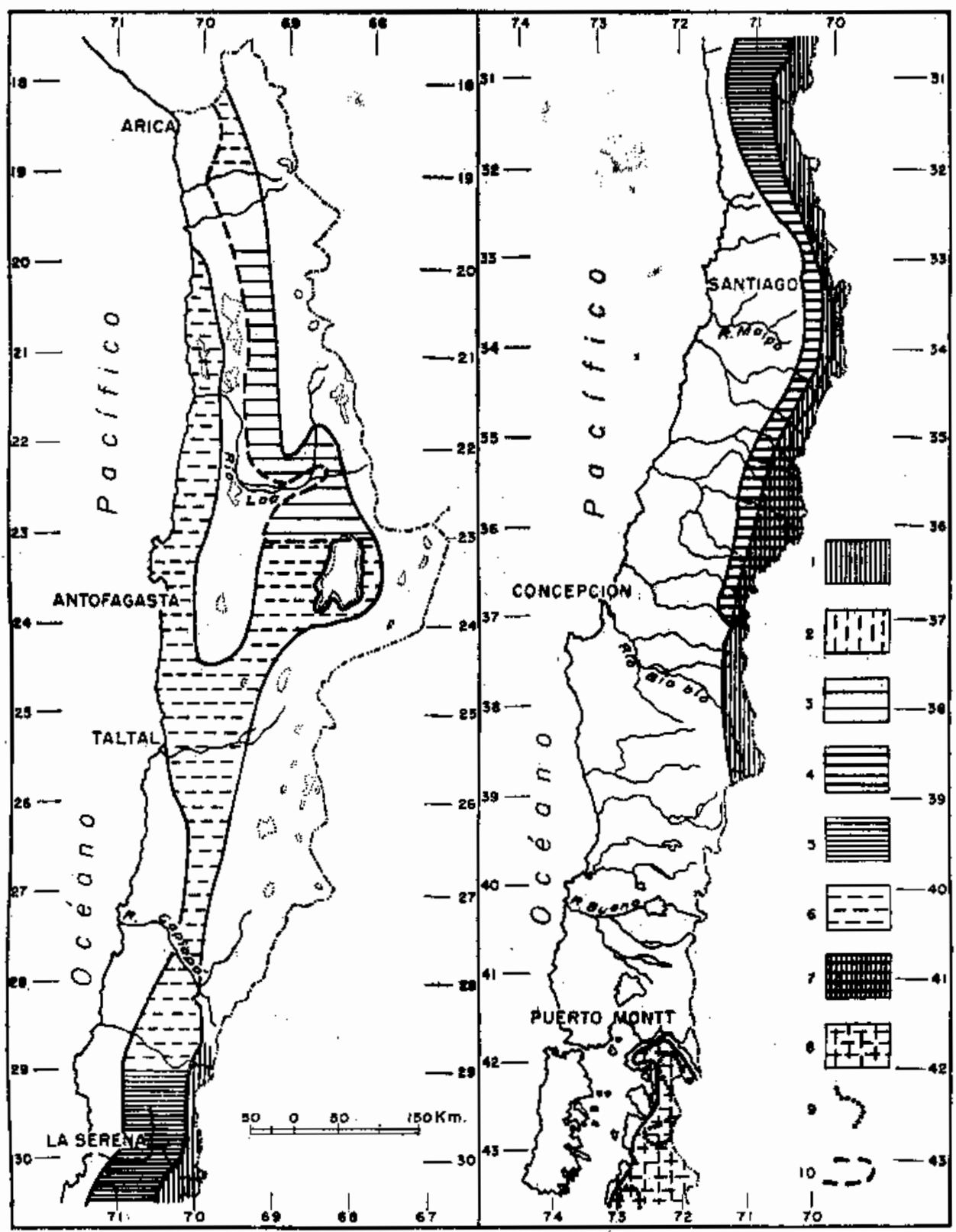

Fig. 15. Avalanchas y corrientes de barro en Chile.

Regiones de avalanchas: 1) Seguras; 2) Probabłes. Regiones de corrientes de barro de origen pluvial o plutio-nival: 3) Seguras, con débil intensidad; 4) Seguras, con intensidad media; 5) Segura y de gran intensidad; 6) Probables. Regiones que presentan avalanchas y corrientes de borro: 7) Seguras; 8) Probables; 9) Limite inferiox de la zona probable de corrientes de barro de origen glacial; 10) Limite occidental y mcridional de las corrientes de barro estivales. 
su naturaleza en Chile, muestra la existencia de fenómenos peligrosos cuya significación gográfica no escapará al lector, en particular con referencia a sectores de colonización o de construcciones futuras (Fig. 15).

La zona de seguro peligro de avalanchas en el Norte Chico y Chile Central se basa en datos de caídas de aludes a los que se agregó el análisis de las condiciones naturales. Bajo beneficio de inventario deben considerarse las zonas marcadas como peligrosas en las hoyas del Huasco, Choapa, Ligua, Petorca y alto Bío-Bio.

AI sur del paralelo $42^{\circ} \mathrm{S}$,, el contorno de la zona de peligro con avalanchas probables debe también considerarse como sujeta a revisión.

La ausencia de datos ha hecho imposible establecer la intensidad de la actividad de avalanchas.

Las zonas de corrientes de barro de origen pluvial o nivo-pluvial también se dividen en el mapa en dos categorfas: aquellas que parecen seguras, establecidas en base a los datos fehacientes y al análisis de condiciones naturales y las que denominamos probables, determinadas sólo en base al análisis geográfico.

En la parte norte de Chile Central la zona de peligro de avalanchas limita con la de corrientes de barro. Al sur de esta misma región la parte superior de la zona de corrientes de barro y la de avalanchas coinciden.

El mapa aquí presente muestra que una parte considerable del territorio de Chile constituye zona de peligro. Sin embargo, a veces la superficie de la zona de peligro está en relación inversá con la intensidad de las avalanchas corrientes de barro. Por ejemplo, parte considerable del Norte Grande está en la zona de peligro de corrientes de batro, pero la cantidad de las quebradas realmente activas es muy baja, como también lo es la frecuencia de las corrientes de barro, por lo cual la región es finalmente de poco peligro.

En Chile Central, al contrario, la zona amenazada por corrientes de barro es angosta, pero caracterizada por una alta intensidad, la colonización de este territorio se vería seriamente afectada por este fenómeno, así como por las avalanchas.

En resumen, quisiéramos insistir en que el peligro real aumenta en forma paralela a la colonización de las montañas. Por ello el interés de los científicos y gobernantes chilenos frente a los problemas de las avalanchas y corrientes de barro crecerá a medida que el hombre penetre en la Cordillera de los Andes.

\section{BIBLIOGRAFIA}

Bogomolova, I. V. Las corrientes de barro $y$ su distribución en el territorio de la úrss. (En ruso). Leningrado, 1957 .

BORDE, J. Las incidencias cataclísmicas en la morfologia de los Andes de Santiago. Informaciones Geográficas, 1960. Santiago de Chile, 1968.
Bökrer., R. Mapa Geomorfológico de Chile. Santiago de Chile, 1965.

Castillo, L. O. El agua stibtertanea en el norte de la Pampa del Tamarugal. Instituto de Investigaciones Geologicas. Chile. Bolctín N0 5. Santiago de Chile, 1960.

- Climatologia die Chile. Fasciculo I. Valores 
normales de 36 cstaciones seleccionadas. Periodo 1916-1945. Proyecto hidrometeorológico. Naciones Unidas. Gobierno de Chile. Santiago de Chile, 1964.

- Corrientes de barro en la uRss. (En ruso). Moscú, 1964.

- Diccionario Hidrológico en Lenguas Extranjeras. (En ruso). Leningrado, 1966.

- Geografia Económica de Chile. corfo. San. tiago de Chile, 1964.

Golubev, G. N. Corrientes de barro de origen glacial. (En ruso). Vestinik Moscovscogo Universiteta (Noticias de Ia Universidad de Moscú). Geografía No 4, 1964.
KuzMin, P. P. El proceso del derretimiento de la capa de nieve. (En ruso). Leningrado, 1961.

Lucachova, E. N. América del Sur. Geografia Fisica. (En ruso). Moscu, 1958.

Lliboutry, L. Nieves y glaciares de Chile, Fun. damentos de glaciologia. Santiago de Chile, 1956.

Puzanov, v. P. Sobre la apreciación cuantitativa de la importancia de factores de abla. ción de la capa die nieve. (En ruso). En el libro Nieves y Aguas de fusion. Moscú, 1956 .

Tuchissky, G. K. Avalanchas, Moscú, 1949. 